\title{
A review of micro-powder injection moulding as a microfabrication technique
}

\author{
Usama M Attia ${ }^{1}$ and Jeffrey R Alcock ${ }^{2}$ \\ 1 Building 56, Cranfield University, Wharley End, Cranfield, Bedfordshire, MK43 0AL, UK. E-mail: $\underline{\text { u.attia@cranfield.ac.uk }}$ \\ 2 Building 61, Cranfield University, Wharley End, Cranfield, Bedfordshire, MK43 0AL, UK. E-mail: j.r.alcock@cranfield.ac.uk
}

\begin{abstract}
Micro-powder injection moulding ( $\mu \mathrm{PIM})$ is a fast-developing micro-manufacturing technique for the production of metal and ceramic components. Shape complexity, dimensional accuracy, replication fidelity, material variety combined with high-volume capabilities are some of the key advantages of the technology. This paper assesses the capabilities and limitations of $\mu$ PIM as a micromanufacturing technique by reviewing the latest developments in the area and by considering potential improvements. The basic elements of the process chain, variant processes and simulation attempts are discussed and evaluated. Challenges and research gaps are highlighted, and potential areas for improvement are presented.
\end{abstract}

Keywords: Micro-powder injection moulding, microfabrication, powder metallurgy

PACS: 81.20.-n, 81.16.-c, 81.20.Ev, 81.20.Wk, 85.85.+j, 87.85.Va, 07.10.Cm, 87.80.Ek, 83.50.Uv

\section{Introduction}

\subsection{Aim of the paper}

Micro-powder injection moulding ( $\mu$ PIM) is a developing micromoulding technology which is now being used for the high-volume microfabrication of metal and ceramic components. However, unlike high-volume microfabrication processes, such as micro-polymer injection moulding ( $\mu \mathrm{IM})$ and micro-hot embossing $(\mu \mathrm{HE})$, aside from several brief process overviews it has yet to be systematically reviewed [1-3].

This review, therefore, covers major advances in $\mu$ PIM since its early stages in the late nineties [4-9], when advances in micro-mould making techniques and dedicated micro-moulding equipment raised the possibility of micro-moulding of metals and ceramics.

The aim of this paper is to review $\mu$ PIM as a high-volume micro-manufacturing technique for the production of metal and ceramic "micro-components", i.e. components which fall into one or more of the following three classes [10,11]:

- Micro-parts: parts with a maximum size below $10 \mathrm{~mm}$ and features in the micron range [3]. 
- Microstructured parts: parts with dimensions between several millimetres and several centimetres with three-dimensional microstructures located on one or more surface area [3,12].

- Micro-precision parts: parts of unlimited size, but with tolerances in the micron range or smaller [13].

\subsection{Structure of the review}

$\mu$ PIM generally follows a specific process chain in which a metal or ceramic powder is mixed with a binder, the mix moulded, the binder removed and the powder then sintered (see Figure 1). These process steps have been used here as the central structure of the review. Section 3 discusses feedstock requirements for $\mu \mathrm{PIM}$, Section 4 deals with mould-fabrication, Section 5 presents the injection moulding of "green compacts" and Section 6 discusses debinding of micro-components. Sintering in $\mu \mathrm{PIM}$ is discussed in Section 7 and Section 8 presents inspection and metrology.

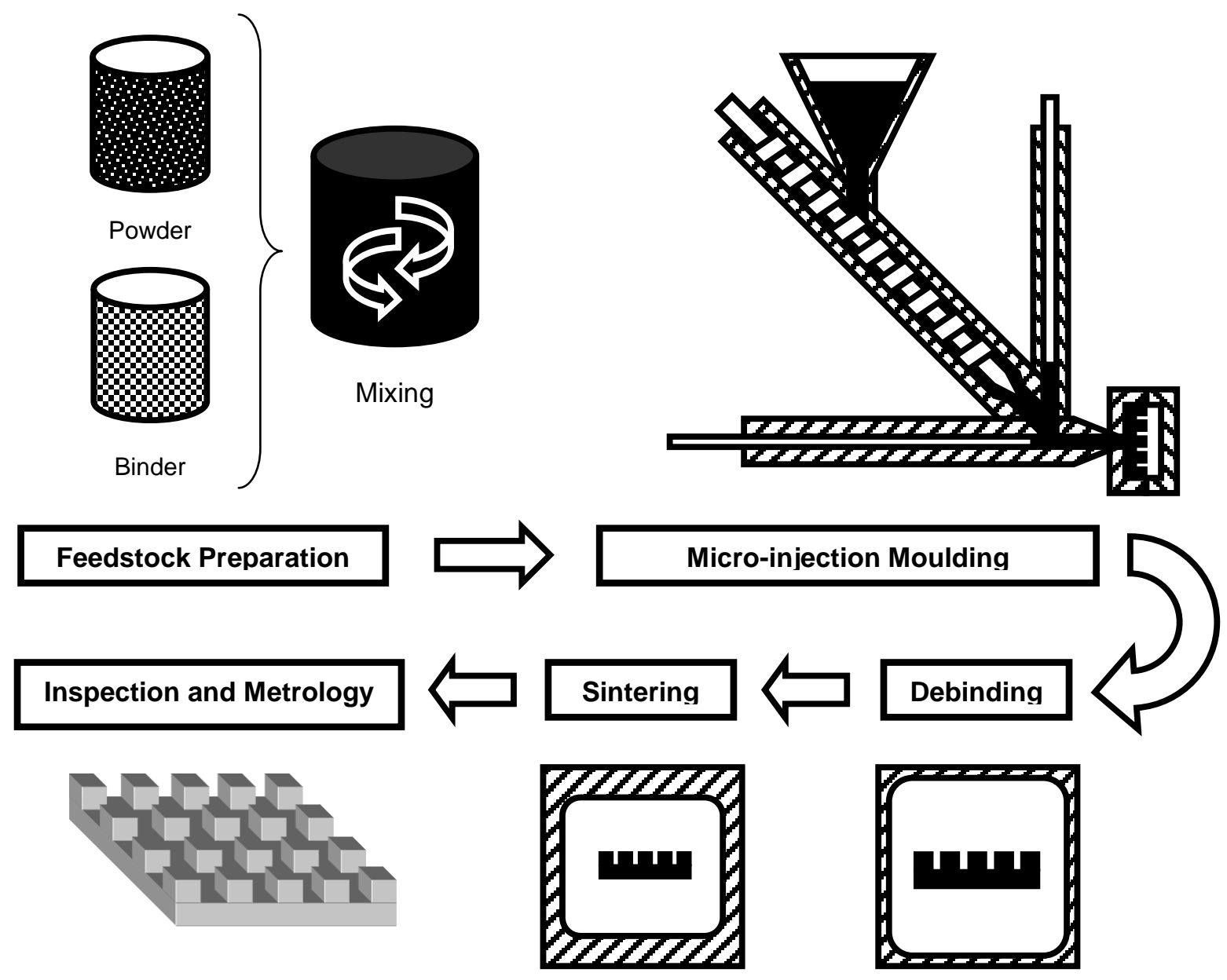

Figure 1. Process chain for $\mu$ PIM. 
Three further sections of this review cover: the design of parts for $\mu$ PIM (Section 2), initial attempts at numerical simulation of the process (section 9) and process variants, such as twocomponent $\mu$ PIM (Section 10).

It should be noted that in some sections of the review, information is adopted from other domains, such as polymer micro-injection moulding ( $\mu \mathrm{IM}$ ), conventional injection moulding (IM) and conventional powder injection moulding (PIM). This is done where the state of the art in these domains also represents what is currently known about $\mu$ PIM. This is predominantly the case for $\mu \mathrm{PIM}$ as a near-net-shape manufacturing technique and as a technique based on polymer flow. Therefore out of domain information is presented concerning (a) design guidelines, e.g. mould fabrication (section 2), (b) processing steps, e.g. moulding and demoulding (section 4) and (c) flow properties, e.g. rheological performance and micro-cavity filling (section 5).

\section{Designing for $\mu \mathrm{PIM}$ of micro-components}

As most of the reported work presents individual case studies that are intended for lab-based prototyping, no comprehensive design rules have been set yet for designing micro-components for $\mu \mathrm{PIM}$. It is a common concern among several active groups in $\mu \mathrm{PIM}$ that design information is poorly documented and case studies are missing [3].

On the other hand, being a net-shape process, several design guidelines for $\mu$ PIM are similar in principle to other net-shape processes that involve shaping a defined volume of material inside a form. It has therefore been suggested that, as a general design rule for conventional PIM, if a shape can be formed from plastic, then PIM is viable. This applies to design criteria of wall thickness, overall component size, component weight, and internal cavity shape [14]. This assumption would also be valid on the micro-scale, in the sense that design rules for $\mu$ PIM are similar to that of $\mu \mathrm{IM}$ of polymers.

General design rules and restrictions for $\mu \mathrm{PIM}$ are essentially similar to those of polymer $\mu \mathrm{IM}$, such as avoidance of closed cavities, undercuts and internal bores. Also design requirements are the same, such as parting lines, gate design and ejectors location. Such generic rules can be found elsewhere [15].

The following sections highlight design issues within the $\mu \mathrm{PIM}$ domain with respect to minimum feature dimensions, achievable aspect ratios and shape deformations.

\subsection{Mouldable dimensions and achievable aspect ratios}

Increasing demands for relatively complex miniaturized components put extra requirements on manufacturable geometries such as feature dimension and/or aspect ratios (AR) - the ratio of feature depth to width. Producing high AR structures by $\mu$ PIM is affected by a number of factors, including powder size, binder system and mould quality [16]. Table 1 shows dimensions and aspect ratios 
achieved with $\mu \mathrm{PIM}$ experiments reported in the literature. This is shown in correlation to the category of micro-component produced, according to the definition used in Section 1.1.

Table 1. A summary of achieved minimum dimensions and maximum aspect ratios produced by $\mu$ PIM for different materials and micro-component categories. MP: Micro-part, MS: Micro-structured part and MPR: Micro-precision part.

\begin{tabular}{|c|c|c|c|c|c|c|}
\hline Material & $\begin{array}{c}\text { Powder } \\
\text { size }\left(d_{50}\right) \\
{[\mu \mathrm{m}]}\end{array}$ & $\begin{array}{c}\text { Min. } \\
\text { feature } \\
\text { dimension } \\
{[\mu \mathrm{m}]}\end{array}$ & REF & $\mathbf{A R}$ & REF & Category \\
\hline \multicolumn{7}{|l|}{ (1) Metals } \\
\hline \multirow{7}{*}{ Carbonyl iron $(\mathrm{Fe})$} & \multirow[t]{2}{*}{1.5} & 20 & [17] & 10 & [17] & - \\
\hline & & 50 & {$[9,18]$} & 14 & [9] & MP, MS, MPS \\
\hline & 2 & $10-30$ & {$[19,20]$} & 5.3 & [20] & MS \\
\hline & 4.5 & 50 & [9] & 14 & [9] & - \\
\hline & 5 & - & - & $\begin{array}{l}1.6-4 \\
\text { depending } \\
\text { on geometry }\end{array}$ & [20] & MS \\
\hline & 10 & 200 & [20] & $\begin{array}{l}0.8 \text { for all } \\
\text { shapes }\end{array}$ & [20] & MS \\
\hline & - & 10 & {$[21]$} & 16 & {$[21]$} & MS \\
\hline \multirow[t]{19}{*}{ Stainless steel (316L) } & - & 100 & {$[12,22-24]$} & 2 & $\begin{array}{l}{[12,22-} \\
24]\end{array}$ & MS \\
\hline & - & 80 & [25] & 2.38 & {$[25]$} & MS \\
\hline & 2 & 100 & [26] & 1 & [26] & MS \\
\hline & 2.4 & 100 & {$[10,27]$} & 2 & {$[10,27]$} & MS \\
\hline & \multirow[t]{4}{*}{3} & 20 & [19] & 2 & {$[22]$} & MS \\
\hline & & 50 & [28] & 4 & [28] & MS \\
\hline & & 80 & [29] & 2.37 & [29] & MS \\
\hline & & 100 & {$[12,22,29]$} & 2 & [12] & MS \\
\hline & \multirow[t]{4}{*}{4} & 20 & [30] & 8 & [30] & MS \\
\hline & & 60 & {$[31,32]$} & 3.2 & {$[31,32]$} & MS \\
\hline & & 80 & [25] & 2.45 & [25] & MS \\
\hline & & 100 & $\begin{array}{l}{[16,23,24,3} \\
2,33]\end{array}$ & $2-2.5$ & $\begin{array}{l}{[16,23,24} \\
, 32,33]\end{array}$ & MS \\
\hline & \multirow[t]{2}{*}{4.5} & 20 & {$[17]$} & 10 & {$[17]$} & - \\
\hline & & 50 & {$[9,18]$} & 10 & [9] & MP \\
\hline & 7.3 & 100 & [34] & 2.5 & [34] & MS \\
\hline & 8.5 & 160 & [35] & - & - & MS \\
\hline & 9 & 50 & [28] & 4 & [28] & MS \\
\hline & 9.8 & 160 & [35] & - & - & MP \\
\hline & 11.2 & 160 & [35] & - & - & MP \\
\hline \multirow[t]{4}{*}{ Stainless steel (17-4PH) } & 3 & 160 & [35] & - & - & MP \\
\hline & 4.6 & 160 & [35] & - & - & MP \\
\hline & 5 & 200 & [36] & 0.14 & [36] & MP \\
\hline & 9.6 & 160 & [35] & - & - & MP \\
\hline \multirow[t]{2}{*}{ Hard metal (WC-Co) } & 0.5 & 20 & {$[19,20]$} & - & - & MS \\
\hline & - & 50 & [9] & 10 & [9] & - \\
\hline Nickel-iron alloy $(\mathrm{NiFe})$ & & 60 & [2] & - & - & MP, MS \\
\hline \multirow[t]{2}{*}{ Copper $(\mathrm{Cu})$} & 0.5 & $20-30$ & [19] & - & - & MS \\
\hline & $<1$ & 10 & [37] & - & - & \\
\hline $\begin{array}{l}\text { Tungsten-copper alloy } \\
\text { (WCu) }\end{array}$ & 1.8 & 30 & [19] & - & - & MS \\
\hline
\end{tabular}


(2) Ceramics

\begin{tabular}{|c|c|c|c|c|c|c|}
\hline Aluminium oxide & $0.17-0.33$ & 2.8 & [38] & - & - & MS \\
\hline \multirow[t]{4}{*}{ (Alumina) $\mathrm{Al}_{2} \mathrm{O}_{3}$} & \multirow[t]{3}{*}{$0.4-0.6$} & 10 & [9] & 14 & [9] & - \\
\hline & & 20 & [18] & - & - & MS \\
\hline & & $<20$ & [17] & $>10$ & {$[17]$} & - \\
\hline & 10 & 100 & [33] & 2.5 & [33] & MS \\
\hline \multirow{4}{*}{$\begin{array}{l}\text { Zirconium oxide } \\
\text { (Zirconia) } \mathrm{ZrO}_{2}\end{array}$} & \multirow[t]{4}{*}{$0.2-0.4$} & $<1$ & [18] & - & - & MS \\
\hline & & $<3$ & [17] & $>10$ & {$[17]$} & - \\
\hline & & 5 & [1] & - & - & MP, MS, MPR \\
\hline & & 10 & [9] & 14 & [9] & - \\
\hline Yttria-stabilised zirconia & 0.3 to 0.4 & 7 & [39] & - & - & MP, MPR \\
\hline \multirow{2}{*}{$\begin{array}{l}\text { Lead zirconate titanate } \\
(\mathrm{PZT})\end{array}$} & - & 20 & [7] & - & - & MP, MPR \\
\hline & 10 & 100 & [33] & 2.5 & [33] & MS \\
\hline
\end{tabular}

It is noted from the table that a relatively wide range of dimensions and aspect ratios have been achieved for both metals and ceramics, where most of the tested micro-components lie within the micro-structured category. This is because most experiments are not directed towards producing specific products but rather towards assessing the capabilities of the process itself using an array of microstructured geometries. In addition, microstructured substrates are relatively easier to produce and handle, since the overall size of the component lies in the millimetre range.

The few micro-part examples are usually limited to micro-sized specimens or micro-gears. Gear structures are sometimes classified as micro-precision components, since they require accurate alignment with other gears or components. Very little is available in the literature about achievable dimensional tolerances by $\mu$ PIM, but typical reported tolerances are between $\pm 0.2 \%$ and $\pm 0.5 \%$ of nominal dimensions $[3,40,41]$. A recent study suggested that with thorough process optimisation accuracies of $\pm 0.1 \%$ of the nominal dimension of some ceramic components could be reached in certain directions of the final part [17,41].

Another observation from the table is that, regardless of the category of micro-component produced, smaller micro-feature dimensions are achievable for ceramics than for metals. This is because minimum feature dimensions are related to the feedstock powder size. A general rule for $\mu \mathrm{PIM}$ is that minimum feature sizes should be at least in the order of ten times the mean particle size, and if smaller features need to be produced then finer powders need to be used [1]. Since it is possible to obtain powder sizes for ceramics that are smaller than those generally achievable for metals, smaller feature sizes for ceramics are achievable (more details about the effect of powder size are given in Section 3.2).

The table also shows a tendency for higher aspect ratios for metals than for ceramics. This is possibly because larger feature sizes for metals offer enough green strength that makes it possible to mould/demould higher aspect ratio features.

It has been reported that currently, the maximum AR for $\mu \mathrm{PIM}$ is 10 , where minimum structural details for metals are $10 \mu \mathrm{m}$ and for ceramics $2 \mu \mathrm{m}$ [13]. Some other references suggested that typical PIM applications with as high AR as 70 have been achieved [42,43]. With respect to minimum 
dimensions, the smallest dimensions that can be achieved are parts with thickness of $25-50 \mu \mathrm{m}$ or minimum structural details of less than $10 \mu \mathrm{m}[40,44]$.

Minimum part weight of $\mu \mathrm{PIM}$ components is decreasing with more miniaturisation achieved with $\mu$ PIM. Reported part weight of $\mu$ PIM components was as small as $0.25 \mathrm{mg}$ for LIGA-replicated gear wheels made of aluminium oxide [18]. For metals components, parts with weights of $7 \mathrm{mg}$ were made by $\mu \mathrm{PIM}$ of $17-4 \mathrm{PH}$, and parts for human ear-bone replacement had the weight of $5.4 \mathrm{mg}$ [1].

$\mu \mathrm{PIM}$ is relatively limited in terms of minimum feature sizes in the sub-millimetre range. This is because the particle size of the feedstock used determines the minimum mouldable dimensions. As feature sizes decrease to $0.1 \mathrm{~mm}$, the required particle size falls below $10 \mu \mathrm{m}$ and only ceramics and stainless steel are available. Below this range, zirconia and alumina are the remaining candidates [44]. As finer powders are currently being developed for metals and ceramics, it is likely that $\mu$ PIM will eventually reach smaller dimensions and higher aspect ratios.

\subsection{Mouldable shapes and geometries}

Very little is available in the literature about the relation between component geometry and filling quality in $\mu \mathrm{PIM}$. Most of the reported $\mu \mathrm{PIM}$ experiments focused on test-structures or prototypes for specific applications. Examples of the micro-part category include micro-gears of different dimensions [19,39,45-47] and micro-dumbbell specimens [39,48]. Examples of microstructured substrates include nozzle structures [39,46], arrays of cylindrical columns [10,22,23,27,29], arrays of micro channels [49,50] and microfluidic structures [1,19,26,51,52].

A few reported examples, however, aimed at understanding the effect of feature geometry on the part quality in $\mu \mathrm{PIM}$. In one experiment it was shown that bar structures are more stable during the ejection step than round structures [19]. In another experiment, a number of geometries were moulded by $\mu \mathrm{PIM}$ and compared, such as cylinders, vertical bars and horizontal bars. The purpose was to check the effect of feature geometry on achievable aspect ratios with respect to powder size. Several shapes were also investigated with respect to polymer content in the binder for the achievable aspect ratio [20].

Different test geometries were also used to verify a computational approach of a simulation technique for $\mu \mathrm{PIM}$. The test geometries were designed to study different effects that can occur during injection moulding, such as bending bars, stepped cross section, diffusers and spiral shapes [53]. Another $\mu$ PIM simulation test implemented four different microfluidic geometries: plain plate, ribbed plate, slotted plate and plate with $250 \mu \mathrm{m}$ deep channel [42] (more details about simulation of $\mu$ PIM are given in Section 9). 


\subsection{Shape deformation in $\mu$ PIM}

Within the process chain of $\mu \mathrm{PIM}$, the three main processes of injection moulding, debinding and sintering take place in a high pressure and/or high temperature environment. Therefore, significant variation in some key parameters, such as volume and warpage, are expected [24].

With regards to part volume, dimensions typically decrease by about $2 \%$ after moulding, but some reported research indicated the possibility of post-moulding dimensional decrease by approximately 6\% [24]. Another 15\% decrease in dimensions might result after sintering. Debinding does not affect dimensional shrinkage significantly due to the remaining binder acting as an adhesive for the part structure [24].

These changes in dimensions during the process chain affect the overall volume of the produced part. Sintering is the most influential step in dimensional variation, which could reach between 14$22 \%[7,29,46]$ and up to $24 \%$ for some commercial feedstocks [39] (more details about sintering are in Section 7). Dimensional control in sintering of micro-miniature components is yet to be understood [3].

With regards to warpage, an experiment has been reported in the literature were warpage was evaluated by measuring the curvature of the part profile [24]. The observed warpage was explained as a result of residual stress and deformation due to demoulding friction between the microstructures and the mould micro-cavities during demoulding. In another experiment, warpage was used as a comparison factor between the quality of micro-mould inserts produced by $\mu$ PIM and those produced by micro-milling [26]. $\mu$ PIM was shown to produce higher degree of warpage relative to micro-milling due to residual stresses during injection moulding. It should be noted that warpage could also result from processing issues, such as uneven flow velocities during injection, or design issues, such as rapid change in cross section [54].

Dimensional changes are usually associated with densification. This affects not only the overall dimensions but also dimensional tolerances that are significant for microstructures [27]. In addition to densification, some experiments suggest that dimensional changes also depend on the structure size, where shrinkage percent tends to increase when structural sizes reduces to $100 \mu \mathrm{m}$ or below [55].

It should also be noted that dimensional variability is affected by processing parameters such as holding pressure in the injection moulding step or heating rate in the sintering step [24] (more details about the effect of process parameters are presented in the relevant sections about moulding, debinding and sintering). It has been shown for $\mu \mathrm{IM}$ of polymers that process parameters affect not only the filling quality of the parts but also the variability in the filling quality [56]. Since $\mu$ PIM involves a relatively complex feedstock and more processing steps compared to $\mu \mathrm{IM}$, it is likely that processing parameters would have more effect on variability in $\mu \mathrm{PIM}$, a relationship that has not been investigated yet within the covered literature. 


\section{Feedstock systems for $\mu$ PIM}

A $\mu$ PIM feedstock consists of the metal or ceramic in powder form and a binder system. The percentage volume of the binder present depends on its properties and those of the powder. Research in $\mu$ PIM started with using commercially available feedstocks used for conventional PIM, but this resulted, in many cases, in defects and in poor shape retention of produced micro-components [1]. Therefore modified feedstock systems has been investigated for $\mu \mathrm{PIM}$, with special focus on material type, powder size, binder composition, mixing ratios and feedstock characterisation.

The following sections review feedstock systems for $\mu$ PIM in terms of powder material, powder loading and particle size, binder systems and feedstock characterisation.

\subsection{Material powders processed by $\mu$ PIM}

Several metals and ceramics have been successfully used for $\mu$ PIM. Table 2 presents a summary of reported metals and ceramics and their corresponding powder sizes. The category of microcomponents produced is also highlighted following the definitions presented in Section 1.1.

Table 2. Metal and ceramic used in $\mu$ PIM: powder size, micro-component categories (MP: Micro-part, MS: Micro-structured part and MPR: Micro-precision part) and powder loading.

\begin{tabular}{|c|c|c|c|c|c|c|}
\hline Materials & REF & Category & $\begin{array}{c}\text { Powder size } \\
\left(\mathbf{d}_{50}\right)[\mathbf{u m}]\end{array}$ & REF & Category & $\begin{array}{c}\text { Powder loading } \\
\text { (vol. \%) and } \\
\text { REF } \\
\end{array}$ \\
\hline (1) Metals & & & & & & \\
\hline \multirow[t]{5}{*}{ Carbonyl iron $(\mathrm{Fe})$} & \multirow[t]{5}{*}{ [40] } & \multirow[t]{5}{*}{$\mathrm{MP}, \mathrm{MS}$} & 1.5 & {$[7,13,18]$} & $\begin{array}{l}\text { MP, MPR, } \\
\text { MS }\end{array}$ & \multirow[t]{5}{*}{54,56 and 58 [57] } \\
\hline & & & 2 & {$[19,20]$} & MS & \\
\hline & & & 4 to 5 & $\begin{array}{l}{[5,6,9,13,20} \\
, 46]\end{array}$ & $\begin{array}{l}\text { MP, MS, } \\
\text { MPR }\end{array}$ & \\
\hline & & & 6.6 & [58] & MP & \\
\hline & & & 10 & [20] & MS & \\
\hline \multirow[t]{16}{*}{ Stainless steel (316L) } & \multirow[t]{16}{*}[12,59-61]{} & $\mathrm{MP}, \mathrm{MS}$ & 0.1 & [62] & - & \multirow{16}{*}{$\begin{array}{l}50[63] \\
52[62] \\
53[42,43] \\
58[10,16,64-66] \\
60[47,67,68] \\
61.5 \text { and } 62.5[69] \\
65[28] \\
86 \text { (by weight) } \\
{[34]} \\
92 \text { (by weight) } \\
{[22,29]}\end{array}$} \\
\hline & & MPR & 2 & [26] & MS & \\
\hline & & & 2.37 & $\begin{array}{l}{[25,27,64-} \\
66]\end{array}$ & MS & \\
\hline & & & 2.4 & {$[10]$} & MS & \\
\hline & & & 3 & $\begin{array}{l}{[12,19,22,2} \\
8,29,51]\end{array}$ & MS & \\
\hline & & & 3.4 & {$[68]$} & MP & \\
\hline & & & 4 & $\begin{array}{l}{[23,24,31-} \\
33,47]\end{array}$ & MS & \\
\hline & & & 4.5 & {$[13,18]$} & $\begin{array}{l}\text { MP, MS, } \\
\text { MPR }\end{array}$ & \\
\hline & & & 5 & [62] & - & \\
\hline & & & 5.96 & [69] & - & \\
\hline & & & 6.2 & [8] & MS & \\
\hline & & & 8.5 & [35] & MP & \\
\hline & & & 9 & [28] & MS & \\
\hline & & & 9.8 & [35] & MP & \\
\hline & & & 10.5 & [67] & MP & \\
\hline & & & 11.2 & [35] & MP & \\
\hline \multirow[t]{6}{*}{ Stainless steel (17-4PH) } & {$[2,13,14,22,4$} & MP, MS & 2 & {$[45,72]$} & MPR & \multirow[t]{6}{*}{$60[72]$} \\
\hline & $0,70,71]$ & & 3 & [35] & MP & \\
\hline & & & 3.3 & [58] & MP & \\
\hline & & & 4 & {$[1]$} & $\begin{array}{l}\text { MP, MS, } \\
\text { MPR }\end{array}$ & \\
\hline & & & 4.6 & [35] & MP & \\
\hline & & & 9.6 & [35] & MP & \\
\hline
\end{tabular}




\begin{tabular}{|c|c|c|c|c|c|c|}
\hline Nickel (Ni) & [59] & $\mathrm{MP}, \mathrm{MS}$ & - & - & $\begin{array}{l}\text { MP, MS, } \\
\text { MPR }\end{array}$ & - \\
\hline Hard metal (WC-Co) & {$[20,22]$} & MS & 0.5 & [19] & MS & - \\
\hline Nickel-iron alloy (NiFe) & [2] & $\mathrm{MP}, \mathrm{MS}$ & - & - & $\mathrm{MP}, \mathrm{MS}$ & - \\
\hline \multirow[t]{3}{*}{ Tungsten $(\mathrm{W})$} & & $\mathrm{MP}, \mathrm{MS}$ & 1 & {$[40]$} & $\mathrm{MP}, \mathrm{MS}$ & \multirow[t]{3}{*}{$55[73]$} \\
\hline & & & $1.43-1.7$ & [73] & $\mathrm{MP}, \mathrm{MS}$ & \\
\hline & & & 2.5 & [40] & $\mathrm{MP}, \mathrm{MS}$ & \\
\hline Tungsten carbide & [40] & MP, MS & - & - & MP, MS & - \\
\hline Tungsten-copper alloy (WCu) & [74] & MS & 1.8 & [19] & MS & - \\
\hline \multirow{3}{*}{ Copper $(\mathrm{Cu})$} & \multirow{3}{*}{ [19] } & \multirow[t]{3}{*}{ MS } & 0.13 & [75] & - & Variable \\
\hline & & & 0.5 & [19] & MS & - \\
\hline & & & 7.8 & [75] & - & Variable \\
\hline $\begin{array}{l}\text { Molybdenum-copper alloy } \\
(\mathrm{MoCu})\end{array}$ & [74] & MS & - & - & - & - \\
\hline \multirow[t]{2}{*}{ Titanium (Ti) } & \multirow[t]{2}{*}[61]{} & \multirow[t]{2}{*}{$\mathrm{MP}, \mathrm{MS}$} & 23 & {$[48]$} & $\mathrm{MP}, \mathrm{MS}$ & - \\
\hline & & & 24 & {$[76]$} & MP & $60[76]$ \\
\hline \multicolumn{7}{|l|}{ (2) Ceramics } \\
\hline \multirow{6}{*}{$\begin{array}{l}\text { Aluminium oxide (Alumina) } \\
\mathrm{Al}_{2} \mathrm{O}_{3}\end{array}$} & \multirow[t]{6}{*}[2,22,59,60]{} & \multirow{6}{*}{$\begin{array}{l}\text { MP, MS, } \\
\text { MPR }\end{array}$} & $0.17-0.33$ & {$[38,77]$} & MS & \multirow{6}{*}{$\begin{array}{l}50-51.2[38] \\
50-60[78,79]\end{array}$} \\
\hline & & & 0.26 & {$[80]$} & MP & \\
\hline & & & $0.4-0.6$ & $\begin{array}{l}{[9,13,18,46,} \\
79]\end{array}$ & $\begin{array}{l}\text { MP, MS, } \\
\text { MPR }\end{array}$ & \\
\hline & & & 0.7 & {$[80]$} & MP & \\
\hline & & & 0.8 & [78] & MP & \\
\hline & & & 10 & [33] & MS & \\
\hline & {$[2,22,40,59,7$} & MP, MS & 0.15 & [82] & MS & \multirow[t]{4}{*}{$50[53]$} \\
\hline \multirow{3}{*}{$\mathrm{ZrO}_{2}$} & \multirow[t]{3}{*}{$1,81]$} & & 0.63 & {$[80]$} & MP & \\
\hline & & & $0.2-0.44$ & {$[13,18,53]$} & $\begin{array}{l}\text { MP, MS, } \\
\text { MPR }\end{array}$ & \\
\hline & & & 1.02 & {$[80]$} & MP & \\
\hline \multirow[t]{2}{*}{ Yttria-stabilised zirconia } & \multirow[t]{2}{*}{ [39] } & \multirow[t]{2}{*}{ MP, MPR } & 0.05 & {$[83]$} & MP & \multirow{2}{*}{$\begin{array}{l}26,41 \text { and } 45[83] \\
45[70]\end{array}$} \\
\hline & & & $0.3-0.44$ & $\begin{array}{l}{[6,7,9,46,70} \\
]\end{array}$ & $\begin{array}{l}\text { MP, MS, } \\
\text { MPR }\end{array}$ & \\
\hline Silicon nitride $\left(\mathrm{Si}_{3} \mathrm{~N}_{4}\right)$ & {$[2,13,22,40]$} & $\mathrm{MP}, \mathrm{MS}$ & - & - & - & - \\
\hline Titanium oxide $\left(\mathrm{TiO}_{2}\right)$ & {$[2,22]$} & $\begin{array}{l}\text { MP, MS, } \\
\text { MPR }\end{array}$ & 1.6 & {$[84]$} & MS & - \\
\hline Aluminium nitride (AlN) & {$[2,13,22]$} & MS & - & - & MS & - \\
\hline \multirow[t]{2}{*}{ Lead zirconate titanate (PZT) } & \multirow[t]{2}{*}[2,22]{} & \multirow[t]{2}{*}{ MS } & 0.3 & {$[8]$} & MS & - \\
\hline & & & 10 & [33] & MS & - \\
\hline
\end{tabular}

Table 2 shows that most of the common powder-metallurgy and structural ceramic powders have been used in $\mu$ PIM to produce both micro-parts and micro-structured components.

Material selection is highly dependent on the application of the component. Databases are usually consulted for failure conditions and relevant design properties to identify composition and property combinations [14].

Stainless steel 316L has been particularly used for microfluidic applications due to hightemperature resistivity and chemical inertness [42]. Tungsten is used for $\mu \mathrm{PIM}$ for its high density, high thermal conductivity, high strength and yield point, high melting point and low thermal expansion [40].

Powder composition affects special properties that might be relevant to the component application. Examples include magnetic characteristics, heat conductivity, thermal expansion and hardness [47]. Databases and standards for materials suitable for $\mu$ PIM is not currently available, especially for relevant properties such as particle size, impurity and agglomeration [3].

Ceramic powders, on the other hand, are easier to handle in $\mu$ PIM compared to metallic materials, as the latter are often pyrophoric in the nanopowder size range [1]. In addition, because of 
their relatively lower thermal conductivity, ceramic-based feedstocks tend to less prematurely freeze during injection moulding due to lower cooling rate [19].

\subsection{Powder loading and particle size}

The powder content of the feedstock is an important factor in $\mu$ PIM processing. Experiments suggested that a polymer content of 50-55\% was found to be suitable for good reproduction results, as it is a suitable compromise between shape retention and moulding viscosity $[19,20,40]$. Actual mixing ratios are dependent on several factors, especially the filling behaviour of the feedstock during moulding.

Higher powder loading results in better shape retention, enhances sintering and minimizes shrinkage. However, beyond a certain powder volume percent, the feedstock will be difficult to mix and inhomogeneous, and the high viscosity of the melt would make it unsuitable for moulding [69]. Low powder loading, on the other hand, may result in powder-binder separation under high pressure during processing [69], and may cause difficulties with sintering abilities and achievable densities [85]. It is usually favourable to maximize powder loading whilst keeping the feedstock viscosity as low as possible [85].

In table 2, it is shown that for a particular material, different powder loadings can be used. For stainless steel $316 \mathrm{~L}$, for example, the powder volume loading has ranged between $50 \%$ to $65 \%$. The relatively high powder loading of $65 \%$ was achieved by mixing the powder with a wax-based binder using a twin-screw extruder and was successfully used in replicating micro-structures [28].

Beside powder loading, and important factor in preparing the feedstock for $\mu \mathrm{PIM}$ is particle size. Table 2 shows that for each material, several particle sizes have been used for $\mu$ PIM. Early experiments have been conducted with commercially available sizes, which are relatively large. Specialized powders of relatively smaller sizes have been prepared and tested on a lab scale.

The importance of particle size lies in the fact that several quality parameters are affected by powder size either during the process chain or after the final product has been produced [35]. Some aspects of design and processing controlled by powder size include:

- Minimum thickness: Minimum feature dimensions should be at least 10-20 times the particle size $[3,86]$.

- Sharpness of corners: Particle size limits the sharpness of all corners, since the particle radius is the limiting edge radius [86].

- Replication accuracy: Particle size distribution has a significant influence on the accuracy of the replicated structures [87]. Recommended ranges for $\mu$ PIM are $1-5 \mu \mathrm{m}$ for metals and 0.5 or less for ceramics $[7,35,40,46]$.

- Surface finish: Smaller powder sizes produce micro-structures with lower roughness values (a detailed discussion about surface properties in $\mu$ PIM components is in Section 7) $[40,46,88]$. 
- Shape deformation: Reported experiments showed that shrinkage of sintered parts is increased with decreasing powder size [28].

Due to the significant effect of powder size on part quality, current research focuses on developing powders with relatively small particle size and narrow distribution using techniques such as gas atomisation $[1,7,13]$. Nanopowder is a current area of investigation for $\mu$ PIM $[3,40,62]$, where It is envisaged that developing nanopowders for $\mu$ PIM would enable the replication of features below $10 \mu \mathrm{m}$ in size [59]. Smaller particle sizes have the advantages of providing smaller structural details, giving fairly isotropic behaviour and producing better surface finish [62].

However, as the powder size decreases, other processing challenges are likely to appear. For example, the melt viscosity of the feedstock increases with decreasing powder size until it is likely that the feedstock becomes too viscous to mould [35,69]. In addition, some powders are too reactive to be produced in sizes smaller than $1 \mu \mathrm{m}$ (e.g. Ti) [1]. Another concern is the sintering stresses produced, as it is suggested that decreasing the particle size by a factor of 100 would increases the sintering stresses by the same factor [1,60]. Sintering stresses cause distortion in the component during densification, which could be avoided by longer holding times for the stresses to relax before ramping up the temperature again [1]. Fine powders are also likely to lead to difficulties in attaining a high packing density because of particle agglomeration. The reduction of the size of the capillary pathways between particles may also slow down the debinding process [69].

Nevertheless, some nanopowders have already been developed and tested successfully on a lab scale. Spherical particles of nanopowder of $316 \mathrm{~L}$ with average diameter of $100 \mathrm{~nm}$ are used in $\mu$ PIM to produce micro-components [62,63]. Ceramic powders of $600 \mathrm{~nm}$ and smaller are used for $\mu$ PIM [7,46,60]. W-Cu nanocomposite powder was also tested with $\mu \mathrm{PIM}[89]$.

Another area of investigation is the feasibility of using hybrid micro/nano powders for $\mu$ PIM. In one experiment, a bi-modal powder feed stock was formed from micro- and nano particles of copper with $\mathrm{D}_{50}$ of $7.8 \mu \mathrm{m}$ and $130 \mathrm{~nm}$, respectively [75]. Increasing the volume fraction of copper nanopowder led to a decrease in melt viscosity and an increase in grain growth of sintered parts. On the other hand, increasing the volume fraction of nanopowder from 0 to $50 \%$ led to a significant deterioration in surface roughness $\left(\mathrm{R}_{\mathrm{a}}\right)$ from 1-2 $\mu \mathrm{m}$ up to 3-4 $\mu \mathrm{m}$ and a decrease in tensile strength from $250 \mathrm{MPa}$ down to 100-150 MPa.

\subsection{Binder systems}

Binder systems give fluidity to the feedstock and shape retention to the green part [83]. They are also important for regulating the viscosity of the feedstock and, hence, ensuring defect-free processing during $\mu$ PIM. Binder systems usually consist of a major binder (usually a polymer), a minor binder and various processing aids, such as surface modifiers and plasticizers [63]. Surfactants are usually 
added to binder systems to improve the binder properties such as surface wetting, spreading, adsorption and binder strengthening [69].

Basic requirements for binder systems include $[5,21,31,39,62,85]$ : a relatively low viscosity to ensure complete filling of mould micro-cavities, relatively high mechanical stability to ensure safe demoulding, good shape retention and lower shrinkage during debinding and sintering. In addition, the binder has to wet the powder particles completely to avoid agglomeration and shrinkage cavities.

Commonly used binder systems include: polyolefin/wax compounds and POM (polyacetal)based systems. The former has been used extensively (usually with LDPE or HDPE) for subsequent thermal debinding $[7,10,22,29,29,46]$, whilst the latter has been used together with catalytic debinding $[7,13,24,31,32,45,46,90]$ (debinding methods are discussed in detail in Section 6). Other debinding systems have been used for $\mu$ PIM on a smaller scale, such as PAN 250 (a patented binder) $[16,29,33]$, PVA-based binders [33] and EVA (ethylene vinyl acetate)-based binders [8,33]. Different binder systems have been used in $\mu \mathrm{PIM}$ to produce all categories of micro-components, i.e. micro-part, micro-structured parts and micro-precision parts. Within the reviewed literature, no specific preference for binder selection is highlighted with respect to the category of component produced.

Some binders are available commercially, whilst others are prepared on a lab scale. This is usually done by mixing powder with the binder system in small batches using a torque rheometer to evaluate the homogeneity of the mixture, which is measured by the stability of the mixture versus the powder content. Twin-screw compounders are then used to mix the feedstock $[22,29]$.

Some research activities aim at developing binder systems with higher mechanical strength and stiffness for a better demoulding behaviour and higher achievable aspect ratio [18]. In addition, some research work focused on modifying binder systems by adding coarse polymeric spherical particles as sacrificial "spacers" inside the feedstock to control the porosity of the final sintered micro-component [91]. Another challenge under investigation is material homogeneity and its effect on binder/powder separation during micro-moulding [49].

\subsection{Feedstock characterisation}

Characterising the feedstock is important in determining its applicability to micro-moulding in terms of flow behaviour and also the advised process conditions such as melt and mould temperatures. Similar to pure polymers, $\mu$ PIM feedstocks usually exhibit pseudoplastic (shear-thinning) flow behaviour, where melt viscosity decreases with increasing shear rate, and the viscosity decreased with increasing temperature $[22,31,47,69,79]$.

Capillary rheometers are typically used to characterize the rheological performance of the feedstock $[22,31,50,53,61,69]$. However, no information on the required sample size is given in the literature. In some cases, a rotational rheometer was used to examine the viscoelastic properties of different binder systems for nanopowders by plotting the storage and loss moduli, G' and G', of feedstocks $[62,63]$. For conventional PIM, it is recommended that melt viscosity of the feedstock 
should be <1000 Pa.s for shear rate ranges between 100-1000 $\mathrm{s}^{-1}$ [92]. Lower viscosity values are likely to be desired for $\mu \mathrm{PIM}$, since micro-cavities are more challenging to fill before premature freezing takes place.

Thermal properties of feedstocks are typically evaluated using DSC plots to determine the glasstransition and the melt temperatures, $\mathrm{T}_{\mathrm{g}}$ and $\mathrm{T}_{\mathrm{m}}$ respectively for the feedstock. Thermogravimetric calorimetry tests using TGA were used to determine the degradation temperature of the feedstock $[12,22,23,31,47]$. In $\mu$ PIM, the melt temperatures are usually set safely above $T_{m}$ and below the degradation temperature, whilst the mould temperature is typically set below the $\mathrm{T}_{\mathrm{g}}$.

Some other techniques were used to characterize feedstocks for different purposes. Examples include using laser-flash method to measure thermal diffusivity [29], using Sessile Drop Technique to measure contact angle and surface tension between the feedstock and mould material [53] and using a melt-flow indexer to measure the melt-flow index (MFI) of the feedstock [35].

\subsection{Outlook}

With regard to the future of $\mu$ PIM feedstock systems, developments are expected in a number of directions:

- New materials are being developed for $\mu$ PIM. Alloyed steels and non-oxide ceramic powders with mechanical strength and relatively high thermal conductivities are one example [18]. Copper, copper alloys and magnetic materials are also potential candidates [19].

- Low-viscosity feedstock systems are of particular interest for $\mu$ PIM to improve the flow properties and, hence, the filling quality of the moulded components [69].

- Tailor-made feedstock with sub-micron or nano-range powder sizes would be an important improvement for $\mu \mathrm{PIM}$ in terms of replication fidelity, dimensional accuracy and surface properties [1].

- Surface modification of powders is being investigated to produce a more homogeneous feedstock mixture and decrease debinding time [93].

- Environmentally-friendly binder systems, such as water-soluble binders, are being investigated. Recent experiments have demonstrated the use of hydrosoluble binder systems with $\mu$ PIM of alumina [38].

\section{Micromould manufacturing}

A number of manufacturing routes have been developed for micro-structuring mould inserts for micro-moulding in general. Such manufacturing routes produce micro-structures with different properties and limitations in terms of produced geometry, minimum dimensions, maximum aspect ratios, resolution, surface roughness and typical insert materials. Table 3 summarizes basic properties for common micro-manufacturing techniques compiled from different sources [94-98]. 
The techniques shown in table 3 are generally used for producing moulds for different micromoulding process, such as $\mu \mathrm{IM}$ and $\mu \mathrm{HE}$. They are listed, since no preferable methods have been specifically recommended for $\mu$ PIM moulds in the reviewed literature. In addition to common micromanufacturing methods mentioned in table 3 , newly developed techniques for producing micromoulds have been demonstarted, such as micro-hot-embossing of metallic glasses [99].

Table 3. A summary of basic properties for common micro-manufacturing technique for mould inserts.

\begin{tabular}{|c|c|c|c|c|c|c|c|c|}
\hline \multirow[t]{2}{*}{ Process } & \multirow[t]{2}{*}{ Geometry } & \multirow[t]{2}{*}{ Typical materials } & \multicolumn{2}{|c|}{$\begin{array}{c}\text { Feature Accuracy } \\
{[\mu \mathrm{m}]}\end{array}$} & \multirow{2}{*}{$\begin{array}{c}\text { Min. } \\
\text { channel } \\
\text { width }[\mu \mathrm{m}]\end{array}$} & \multirow{2}{*}{$\begin{array}{c}\text { Max. } \\
\text { channel } \\
\text { depth }[\mu \mathrm{m}]\end{array}$} & \multirow[t]{2}{*}{$\begin{array}{l}\text { Max. Aspect } \\
\text { ratio }\end{array}$} & \multirow[t]{2}{*}{$\begin{array}{c}\text { Roughness } \\
\mathbf{R}_{\mathrm{a}}(\mu \mathrm{m})\end{array}$} \\
\hline & & & X-Y & $\mathbf{Z}$ & & & & \\
\hline $\begin{array}{l}\text { Photoresist } \\
\text { processes }\end{array}$ & $21 / 2-D$ & SU-8, polyimide & 2 & $1-5$ & 5 & 200 & 20 & - \\
\hline Silicon Etching & $21 / 2-D$ & Silicon & 5 & $1-5$ & 10 & 500 & 10 & - \\
\hline Micromilling & $3-\mathrm{D}$ & Metals, polymers & $\begin{array}{l}\text { Depends on } \\
\text { material } \\
\text { and feature }\end{array}$ & $3-10$ & $20-200$ & $\begin{array}{l}\text { Depends on } \\
\text { the tool } \\
\text { diameter }\end{array}$ & $\begin{array}{l}7.5 \text { for holes } \\
\text { and pins; } \\
10-15 \text { for } \\
\text { channels }\end{array}$ & 0.3 \\
\hline $\begin{array}{l}\text { Laser micro- } \\
\text { machining }\end{array}$ & $21 / 2-D$ & $\begin{array}{l}\text { Metals, polymers, } \\
\text { ceramics and glass }\end{array}$ & $1-20$ & $3-10$ & $20-200$ & - & 7.5 & 0.1 \\
\hline $\begin{array}{l}\text { Micro-electro- } \\
\text { discharge } \\
\text { machining } \\
(\mu-E D M)\end{array}$ & $3-\mathrm{D}$ & $\begin{array}{l}\text { Hard and brittle } \\
\text { materials for tool } \\
\text { making }\end{array}$ & $1-3$ & - & $50-150$ & - & $10-50$ & $0.4-0.5$ \\
\hline LIGA & $21 / 2-D$ & $\begin{array}{l}\text { Nickel, gold and } \\
\text { ceramic }\end{array}$ & 1 & - & - & $\begin{array}{c}100 \text { up to } 1 \\
\mathrm{~cm}\end{array}$ & 100 & 0.02 \\
\hline $\begin{array}{l}\text { Electro- } \\
\text { chemical } \\
\text { machining }\end{array}$ & $21 / 2-D$ & Silicon and copper & 2 & - & $0.2-10$ & - & 10 & - \\
\hline
\end{tabular}

Among the techniques listed in table 3, silicon etching, in particular, has been popular in making 2-D microstructures (arrays of columns or holes) for $\mu$ PIM mould inserts [10,18-20,22,23,2729,32,33]. LIGA has also been used a number of times as a possible techniques [7,18-20,28,46,70,90], particularly for its relatively small surface roughness.

Other techniques, such as micro-cutting processes [7,18-20,28], laser ablation [7,8,18-20,28] and $\mu \mathrm{EDM}[1,88]$ were used to produce mould inserts of steel, nickel or brass and aluminium alloys, depending on the technique. UV photolithography of SU-8 has also been used for $\mu$ PIM moulds [63].

As seen from table 3, the category of micro-component produced might affect the selection of mould making technique. 2⿺辶2-D features are typically common for micro-structured components, such as micro-column arrays or microfluidics, and in the literature these were usually replicated from micro-moulds produced by silicon etching or LIGA. For micro-parts, the selection of the mouldmaking technique depends on the part geometry, where relatively complex geometries might require the use the 3-D techniques such as micro-milling or $\mu$-EDM. Micro-precision components require moulds that are produced with relatively high dimensional accuracy, where LIGA or etching techniques would be necessary.

Some modifications to the conventional mould design have been introduced to expand the capabilities of moulds for microfabrication. Examples include the use of Variothermal systems 
$[1,19,30,31,36,39,100]$ for complete filling of microfeatures and the so-called twisting tools [71] that are used for producing complex-shaped components. Another example is the integration of ultrasonic sensors onto the micromould insert for real-time process diagnosis of $\mu \mathrm{PIM}$ of ceramic components [101].

Very little is available in the literature about the effect of the feedstock on the tool tolerances in a mass-manufacturing environment. This is likely to be a decisive factor when using $\mu$ PIM for highvolume production, since most of the primary micro-structuring techniques work with relatively soft materials [18]. It has been reported that nickel mould inserts could withstand more than five hundred injection moulding cycles, mostly with automated machine operation without detecting wear phenomena in the nickel mould inserts $[7,18]$. A study on the wear behaviour of micro-moulds for $\mu \mathrm{PIM}$ reported that wear-resistance of micro-moulds is dependent on a number of factors, including hardness, surface condition, homogeneity of the mould insert material in addition to the characteristics of the feedstock [102].

Recent experiments have investigated the effect of diamond-like carbon (DLC) coatings on the lifetime and replication quality of silicon micro-mould inserts [103-105]. Silicon micro-moulds coated with nitrogen and nickel doped DLC (N:DLC:Ni) showed better replication quality and longer lifetime from 3-18 times during micro-hot-embossing of PMMA microfluidic features [105]. An improvement in lifetime was also witnessed in silicon micro-moulds coated with silicon- and nitrogen-doped DLC (Si-N-DLC) during micro-hot-embossing of cyclic olefin copolymer (COC) microfluidic features [104].

In one experiment, the wear behaviour of mould inserts made of different steels, nickel and brass was investigated after moulding with metal and ceramic feedstock [106]. It was shown that high injection pressure and velocity during $\mu \mathrm{PIM}$ typically results in abrasive and/or erosive wear of the mould insert. This is a potential research gap, as the demand for higher abrasion-resistant moulds increases.

Another ongoing development area is the development of tools for multi-material $\mu$ PIM that allows two materials to be sequentially injected [40]. Automation of the $\mu$ PIM process has also been investigated $[107,108]$, which includes the automation of e.g. sprue separation and demoulding.

\section{Micro injection moulding}

Injection moulding is a challenging step in $\mu \mathrm{PIM}$, since the quality of the produced "green" part has a significant effect on the overall final quality of the part with respect to feature accuracy. A considerable amount of injection moulding know-how is already available for conventional (macro) moulding of polymers $[109,110]$ and powders [92]. On the micro-scale, injection moulding of polymers have also been reviewed in the literature $[11,111]$. This section aims, therefore, at presenting the main challenges and major advances in the injection moulding stage of $\mu \mathrm{PIM}$. 
One challenge in $\mu \mathrm{PIM}$ is the ability to completely fill micro-scale cavities $[23,28]$, knowing that the feedstock has a relatively high thermal conductivity, which leads to higher risk of premature freezing of the feedstock during injection $[1,19]$. Another concern in micromoulding of powders is the ejection (demoulding) of the green part, where micro-features are relatively fragile and might collapse or significantly deform during ejection [28].

Investigations of micro-moulding of powders focus on achieving the complete filling of the mould cavities by avoiding premature freezing or excessive filling. Filling quality in micro-moulding depends on a number of factors, including the geometry of the cavity, the rheology of the feedstock and the process conditions.

When it comes to the micro-component category, filling micro-structured components is different from filling micro-parts or micro-precision parts due to the so-called "hesitation effect", which is also evident for $\mu \mathrm{IM}$ of polymers [112]. In this effect, the feedstock melt tends to flow more easily into mould cavities with relatively lower resistance areas, i.e. areas of greater cross section. Thus, the melt tends to fill the relatively large substrate completely before entering the microstructured features (especially high-aspect-ratio structures). This results in premature freezing because the filling time of the substrate is usually greater than the freezing time of the micro-feature.

Two approaches are usually followed to ensure complete filling in $\mu$ PIM: the first is to equip the mould with a heating system (known as Variothermal system) that keeps the mould temperature above the $T_{g}$ of the feedstock to ensure the flow of the melt into all cavities during injection. Upon complete filling, the mould temperature is decreased rapidly to ejection temperature of the part $[1,19,31,39]$. This approach has proved effective in the complete filling of micro-cavities, although it requires a more sophisticated mould and a longer cycle time.

The second approach is to optimize the process parameters of the injection moulding machine to achieve complete filling. This is usually done by adjusting the pressures and temperatures and/or speeds of melt flow throughout its path to fill the tiniest cavities in the mould. The common optimisation approach that has been reported in the literature is by changing one parameter at a time and studying its effect on part quality.

In one experiment of micromoulding $316 \mathrm{~L}$, for example, increasing the mould temperature close to the $\mathrm{T}_{\mathrm{g}}$ of the feedstock was shown to be helpful in both replicating micro-features and preventing pull-of of features during ejection. Holding pressure, on the other hand, was shown to be insignificant for filling quality [22]. In another experiment, complete filling of features with a 316L feedstock was shown to be dependent on increasing injection pressure, mould temperature and holding pressure, in addition to vacuum and Variothermal moulding conditions [31]. In a third experiment with 316L feedstock, increasing both holding pressure and time in addition to mould temperature and injection pressure was effective in mould filling [23].

There is a general agreement that an increase in mould temperature is significant in filling micro-structures, since the feedstock viscosity decreases allowing an easier flow inside the tiny mould 
cavities. The discrepancies in determining the effect of other process parameters is typical for $\mu$ PIM and was previously observed with $\mu \mathrm{IM}$ of polymers [11]. This is because the complete filling of micro-cavities in polymer $\mu \mathrm{IM}$ is a factor of several parameters other than process parameters, such as the material rheological properties and the geometry of the cavities [113]. This is likely to be the same for $\mu \mathrm{PIM}$, as experiments have already showed that binder composition has an effect on filling quality during $\mu \mathrm{PIM}[33$ ], an issue that needs further investigation. Powder filling is also a significant factor in complete mould filling, because the feedstock has a higher thermal conductivity relative to polymers. This results in a faster cooling and solidification of the green micro-structures, which makes incomplete filling highly likely [30].

Another major issue with optimising process conditions is the conventional method of varying process parameters one at a time, which is commonly used in industry. This approach requires relatively long experimentation runs when many parameters are involved, and it does not take into consideration possible interactions between different processing steps.

The Design-of-Experiment (DOE) approach has, therefore, introduced as a statistical method for process optimisation [114] in $\mu \mathrm{IM}$. Only recently $\mu \mathrm{PIM}$ experiments started to implement DOE in process optimisation $[43,82,115]$.

\section{Debinding}

Debinding is the longest step in the $\mu \mathrm{PIM}$ process chain, where important debinding parameters include heating rate, holding temperature and holding time. The boundary conditions on heating rate are associated with the a lack of economic feasible in a mass-manufacturing environment at the low rates, and high internal pressures potentially leading to cracking at high rates [47]. Three different methods for debinding are currently under investigation $[7,13,18,46,85]$ :

(1) Debinding by thermal degradation and elimination of the organic components.

(2) Solvent or catalytic debinding processes commonly used for polyacetal-based systems.

(3) Debinding by supercritical carbon dioxide.

Thermal debinding is the most commonly used technique with $\mu \mathrm{PIM}$, and it is typically used for feedstocks with polyolefin/wax debinders [46]. Several experiments have implemented the use of thermal debinding for $\mu \mathrm{PIM}$ to produce micro-components from $316 \mathrm{~L}$ using multi-stage debinding schedules $[10,12,22,25,29,33,35]$. Debinding of stainless steel 17-4PH micro-dumbbells and microgears was also thermally conducted at $600^{\circ} \mathrm{C}$ in $\mathrm{N}_{2}$ environment $[35,45]$. The main limitation of thermal debinding is that it softens the polymer during debinding, which allows for motion that contributes to dimensional variation [14].

Catalytic debinding, on the other hand, is based on hydrolysing the polymer into its monomer components by acid catalysis, a direct solid-gas transition process that prevents the formation of liquid or softened phases, and, thus, prevents deformation of the green part due to gravity or stress relaxation 
[23,24,28,31,100,116-118]. It, therefore, is thought to result in higher dimensional accuracy, tighter tolerances and better surface finish relative to thermal debinding [14].

Commercial POM-based feedstock is currently available for catalytic debinding, such as the Catamold $^{\mathrm{TM}}$ family from BASF [119]. Ceramic microstructures were successfully debinded by catalytic debinding of Catamold ${ }^{\mathrm{TM}}$ TZP-A $[39,90]$. The main limitations of catalytic debinding is the use of concentrated chemicals such as nitric acid for polymer hydrolysis and the production of toxic gases that, such as formaldehyde, need to be burnt out.

Supercritical debinding uses carbon dioxide under supercritical conditions in an autoclave that normally operates at temperatures of more than $60^{\circ} \mathrm{C}$ and pressures of approximately $300 \mathrm{bar}$ $[7,8,120]$. The process is still under development and a proper assessment of supercritical debinding in $\mu \mathrm{PIM}$ is not yet possible. Further modifications will be required to obtain an economically viable process [13].

It is known that debinding time is directly related to the square of the compact thickness [92], so micro-components should have relatively shorter debinding time than larger (macro) components. However, no specific recommendation with this regard has been reported in the reviewed $\mu$ PIM literature.

Different schedules have been reported in the literature for various debinding techniques and types of feedstock. Relatively fast heating rates during debinding was reported to result in defects such as blistering and bloating [26,34] or cracks that might result from pressure build-up and resulting pressure gradients [78]. On the other hand, increasing heating rates during debinding was shown to improve the surface finish of the component after subsequent sintering, and was shown to decrease the formation of oxides during debinding [12].

Since a binder system typically consists of different constituents, stepwise debinding is usually implemented to accommodate each binder constituent [92]. It was recommended that for thermal debinding, fast heating rates $\left(10^{\circ} \mathrm{C} / \mathrm{min}\right)$ should be used up to a temperature near the melting point of the binder system. As the binder components start to decompose, relatively slow heating rates $\left(0.83^{\circ} \mathrm{C} / \mathrm{min}\right)$ should be used in order to prevent potential defects. Higher heating rates could be implemented again once the pores are opened and channels are provided for the gas to escape [34].

Generally speaking, reported heating rates during debinding ranged between $<1^{\circ} \mathrm{C} / \min [12,34]$ up to $7^{\circ} \mathrm{C} / \mathrm{min}[30,100]$ for $316 \mathrm{~L}$. For ceramics, reported heating rates for debinding ranged between $2-5^{\circ} \mathrm{C} / \mathrm{min}$ for Alumina [78] and up to $10^{\circ} \mathrm{C} / \mathrm{min}$ for PZT [33].

\section{Sintering}

Sintering is usually carried out in a conventional sintering furnace, where sintering takes place in cycles. The temperature is increased in stages, where a holding time is applied between each stage. The holding time is used for induced stresses to relax before the temperature is ramped up again to 
another stage and new stresses are induced. This process helps in avoiding distortions of microcomponents during densification [1].

During the final stage of sintering, densification and grain growth occur simultaneously [25,27]. Depending on the material systems, grain growth and densification take place via diffusion with different sinks and sources for the vacancies [25].

Most reported sintering experiments and parameters of $\mu$ PIM were conducted for $316 \mathrm{~L}$ stainless steel components in tube furnaces [22,23,29,33,35]. For ceramics, sintering can take place in air [7,13], whilst for metals sintering takes place under reducing $\mathrm{N}_{2} / \mathrm{H}_{2}$ [13], $\mathrm{H}_{2}[7,13,51]$ or vacuum $[23,29,31,51]$ atmospheres in order to prevent oxidation.

Sintered components produced by $\mu$ PIM achieve relatively good densities compared to the theoretical densities of their material. For metal parts $95 \%-97 \%$ of the theoretical densities were reached, whilst for ceramic parts, $96 \%-99 \%$ of theoretical densities were reached [13,61]. Linear shrinkages of sintered parts are ranging from $15-22 \%$ depending on the composition of the feedstock $[7,46,85]$.

In addition to shrinkage and density, sintering affects the surface roughness of the final part, since roughness of sintered components is the highest surface roughness observed throughout the process chain [24]. Surface properties of sintered components have recently gained increasing attention in $\mu$ PIM research for a number of reasons:

- Tolerances of micro parts are decreasing towards the range of surface roughness [63].

- Surface forces become dominant at the surface-to-volume ratio encountered in micro parts. Such forces (e.g. friction, viscous drag and surface tension) are encountered, in particular, for applications involving fluid flow, surface reaction, wear and lubrication at the interface $[10,12,63]$.

- Some applications of micro-parts have strict requirements on surface roughness that affect friction and wear at the interface [63].

Table 4 lists achieved surface roughness values for different metal and ceramic materials processed by $\mu \mathrm{PIM}$.

Table 4. Surface roughness values of sintered metals and ceramics produced by $\mu$ PIM. $R_{a}$ is arithmetic average of absolute values, $R_{z}$ is the mean peak to valley height and $R_{\max }$ is the maximum peak to valley height.

\begin{tabular}{clllll}
\hline \multicolumn{1}{c}{ MATERIALS } & \multicolumn{1}{c}{$\mathbf{R}_{\mathbf{a}}[\mathbf{u m}]$} & $\mathbf{R}_{\mathbf{z}}[\mathbf{u m}]$ & $\mathbf{R}_{\mathbf{m a x}}[\mathbf{u m}]$ & $\mathbf{R E F}$ \\
\hline \multicolumn{1}{c}{ (1) Metals } & \multicolumn{5}{c}{} \\
\hline Carbonyl iron (Fe) & $0.20-0.35$ & $1.8-2.9$ & 2 & {$[19,20]$} \\
\cline { 2 - 5 } & - & - & 8 & {$[13]$} \\
\cline { 2 - 5 } & - & - & 4 & {$[13,18]$} \\
\hline Stainless steel (316L) & $0.36-0.43$ & $2.8-3.3$ & - & {$[19]$} \\
& 0.5 & - & - & {$[37]$} \\
& $0.5-0.62$ & - & - & {$[26]$} \\
& - & - & 8 & {$[18]$} \\
\hline
\end{tabular}




\begin{tabular}{lllll}
\hline Hard metal (WC-Co) & $0.54-0.64$ & $4.0-5.4$ & 4.5 & {$[19,20]$} \\
\hline Copper $(\mathrm{Cu})$ & 0.62 & 4.6 & - & {$[19]$} \\
\hline
\end{tabular}

(2) Ceramics

\begin{tabular}{lllcc}
\hline $\begin{array}{l}\text { Aluminium oxide (Alumina) } \\
\text { Al2O3 }\end{array}$ & - & - & 3 & {$[13,18]$} \\
\hline $\begin{array}{l}\text { Zirconium oxide (Zirconia) } \\
\text { ZrO2 }\end{array}$ & - & - & 2 & {$[13,18]$} \\
\hline $\begin{array}{l}\text { Yttria-stabilised zirconia } \\
\text { (Catamold@) }\end{array}$ & $0.17-0.19$ & - & - & {$[39]$} \\
\hline
\end{tabular}

As shown in the table, surface roughness values are generally smaller for ceramics than metals, which is an expected observation considering the relatively smaller powder sizes available for ceramics.

Currently, surface roughness values in the range of $R_{a}=0.3-0.6 \mu \mathrm{m}$ and $R_{z}=2-5 \mu \mathrm{m}$ were reached in $\mu$ PIM depending on material and powder particle size $[2,19]$. The best surface qualities obtained were $R_{\max }=2-3 \mu \mathrm{m}$ with ultrafine ceramic powders [40]. Lower values of surface finish are likely to be achieved as the $\mu$ PIM process develops and feedstock systems with smaller particle sizes are introduced [3].

The surface roughness of the mould was shown to have a negligible influence on the surface quality of sintered components. In one experiment the surface roughness $\mathrm{R}_{\mathrm{a}}$ of the mould, the green parts and the sintered parts were compared for different sintering conditions. It was shown that whilst the roughness of the green part increased slightly compared to the mould roughness, the surface roughness values of the sintered part was orders of magnitude higher than the mould values [10].

How sintering conditions affect surface roughness is still under investigation. For example, the effect of sintering temperatures and times on the surface roughness of $316 \mathrm{~L}$ microcomponents was investigated. Different temperature schedules were proposed and tested to achieve the best surface finish for the features and substrates of a column array structure. It was found that $\mathrm{R}_{\mathrm{a}}$ and grain size values for microstructures increased with increasing sintering temperature and time [10,27] (more details about surface roughness characterisation are found in Section 8.3).

In addition to surface roughness, the effect of sintering on other quality parameters is also being examined. For example, densification of micro-features was investigated for a micro-column array, where it was shown that after sintering, micro-size columns have larger grain size and lower porosity compared to the larger substrate that carried the columns, which indicated that size reduction enhances densification [25]. Other experiments focused on modelling sintering kinetics of micro-structures by comparing different models $[25,66]$. It was shown that pores were eliminated and grain-growth increased in addition to an increase in densification in the sintered part as the sintering time and temperature increased $[10,31]$.

Relevant to densification, the effect of sintering conditions on the formation of "dense layers" in $\mu \mathrm{PIM}$ was presented $[27,29,65]$. The outmost regions of the moulded micro-rods comprised a dense 
layer virtually devoid of pores, which increased in thickness as the sintering temperature or time increased. The dense layer was attributed to the use of fine powder size of $3 \mu \mathrm{m}$. The dense layer growth is formed by the ability of hydrogen to diffuse into the micro-size structures interstitially due to its small molecule. Hydrogen then reacts with the oxides that obstruct the formation of metallic bonds between the powder particle, and this reaction, hence, facilitates densification [27].

Whether the formation of a dense layer is observed for micro-scale structures only is still an issue of investigation. The formation of dense layers in micro-scale components was reported by one research group, and was observed for microstructures of the same general shape (arrays of columns) and same feedstock (316L) but different dimensions (column diameters between 60 and $100 \mu \mathrm{m}$ ) and aspect ratios (between 2 and 3.18) [27,29,65]. It should be noted that a similar effect has been observed for conventional PIM, where a dense skin layer is formed near the surface of the component and was attributed to heat conductivity differences between the surface and the interior of the component [121]. For micro-components, however, the proposed cause of dense layers was related to the ability of hydrogen to diffuse into the micro structures, as explained above, rather than differences in heat conductivity that were shown to be insignificant for micro-structures [27].

The relatively more porous core of the structures was thought to be due to failure of the hydrogen gas molecules to displace the internal gas trapped in the pores between the fine powders which would otherwise give way to the hydrogen molecules to effect densification. Virtually no pores existed in the dense layer because of the shorter transport path that enabled the gas entrapped in the interstices at the surface or immediately beneath the surface to diffuse out easily through the open porosity into the atmosphere.

Several sintering temperatures were used to investigate their effect on dimensional accuracy of 316L and 17-4PH stainless steel micro-components. Dimensional accuracy was represented by the coefficient of value percent (CV\%), which was defined as 100x(standard deviation/average value). It was shown that as sintering temperature increases from $1050^{\circ} \mathrm{C}$ to $1350^{\circ} \mathrm{C}, \mathrm{CV} \%$ is down to approximately $0.09 \%$ [35].

With regard to sintering heating rates, some experiments reported the range of heating rates used for e.g. $316 \mathrm{~L}$ micro-components, which included $5^{\circ} \mathrm{C} / \mathrm{min}[26,67], 7^{\circ} \mathrm{C} / \mathrm{min}[30,31,100]$, $10^{\circ} \mathrm{C} / \mathrm{min}$ [34] and up to $12^{\circ} \mathrm{C}$ [67]. Heating rates between $1-5^{\circ} \mathrm{C} / \mathrm{min}$ were also used for $\mu \mathrm{PIM}$ of zirconia [90]. Such heating rates are not particularly different from those typically used for sintering conventional (macro-) components [122].

A few experiments have investigated the effect of sintering heating rates on particular quality parameters. For example, it was show that during the $\mu \mathrm{PIM}$ of $316 \mathrm{~L}$, increasing the sintering heating rate from $5^{\circ} \mathrm{C} / \mathrm{min}$ up to $12^{\circ} \mathrm{C} / \mathrm{min}$ resulted in an increase in part shrinkage from approximately $12 \%$ to $15 \%$ and an increase in final density from $92 \%$ to $96 \%$ of the theoretical density $[67,68]$. In another experiment with $316 \mathrm{~L}$, it was suggested that fast heating rates during sintering will result in a higher 
amount of carbon that is kept in the sintered part, because sintering occurs before all of the organic components have been removed from the part [31].

The effect of sintering heating rates was also investigated for catalytically debinded $316 \mathrm{~L}$ components, where the recommended sintering schedule starts at $600^{\circ} \mathrm{C}$ to remove potentially high amounts of carbon that are left from the debinding process. After a holding time of 1 hour, the temperature was increased to the normal sintering temperature range between $1200^{\circ} \mathrm{C}$ to $1300^{\circ} \mathrm{C}$.

Recent research work focused on applying alternative sintering techniques for microcomponents, such as spark plasma sintering (SPS) [77]. This technique enables rapid densification of metal and ceramic powder components at low temperatures, which helps in controlling grain growth during sintering.

Very little is available in the literature about structured methods for optimising sintering process conditions for micro-components. The effect of sintering conditions on densification, surface properties and mechanical properties is still in early stages.

\section{Inspection and metrology}

Considering the size of micro-components, assessing the quality of the produced parts depends on the ability to measure relevant properties, such as dimensions, weights, roughness values or mechanical properties. Different techniques and instruments have been implemented to inspect microstructures produced by $\mu \mathrm{PIM}$, but the need for specialized equipment for micro-components still persists. This section reviews some inspection methods used to assess different properties of powder micro-components.

\subsection{Dimensions}

Measuring dimensions is particularly important in inspecting $\mu \mathrm{PIM}$ features for evaluating the replication fidelity of green parts and the overall shrinkage of the sintered part. Most reported experiments in the literature were more concerned about the general shape morphology rather than measuring particular dimensions. This was done by using visual methods, such as light optical microscopy [24,29] and scanning electron microscopy (SEM) [5,10,12,25-27,29,33,39].

Some experiments used the same techniques to evaluate shrinkage after sintering [22,29] or measure selected dimensions [24]. Other techniques, such as laser displacement sensing and digital image analysis, were used to measure dimensions of micro-gears [45].

\subsection{Grain growth}

Since the microstructure of $\mu \mathrm{PIM}$ components affects mechanical properties, evaluating densification is of interest in quality assessment [27]. Grain size is measured using SEM [10] or optical microscopes [31]. A common standard technique to measure grain size is by following ASTM 112-96 [123] using the outlined intercept procedure [10,25,27]. 
Image analysis software $[25,27]$ is used to measure porosity and identifying dense layers of $\mu$ PIM components after polishing substructures [27,29].

\subsection{Surface roughness}

As highlighted previously in Section 7, surface properties of $\mu$ PIM products are of considerable importance for applications such as microfluidic channels. Different instruments were used to evaluate surface roughness of sintered components. These include non-contact surface profilometers with vertical scanning interferometry [10,12], atomic force microscopy (AFM) or confocal laser scanning microscopy (CLSM) [10].

\subsection{Mechanical properties}

Standard instruments are used to evaluate some mechanical properties, such as using nanoindenters to measure Young's modulus for 316L [31] or Vicker hardness [45]. Some specialized instruments have been developed for measuring mechanical properties of $\mu$ PIM components. For example, micro-testing facilities have been developed which was equipped with micro-tensile and three-point-bending testing units $[2,67,124]$. Also, micro-hardness measurements were made on the polished cross-sections of the sintered 316L microfeatures using a micro-hardness tester with a Vickers indenter [29]. Residual stresses in zirconia specimens produced by $\mu$ PIM were measured using a diffractometer [125]. Further studies on investigating mechanical properties of $\mu \mathrm{PIM}$ components could be found in the literature [126,127].

\subsection{Other techniques}

In addition to the inspection methods highlighted above, some other properties were of interest, such as part density or tribological behaviour.

Part densities of metal and ceramic parts were measured using the Archimedes principle using deionized water as the immersion medium [10,27,83], where weights were measured to $0.1 \mathrm{mg}$ [10]. Densities of sintered micro-dumbbell specimens were measured using an electronic scale [35].

Tribological behaviour of micro-moulded 316L was investigated. Typical applications are in moving gears and in micro-moulds made by $\mu$ PIM. Ball-on-disk tribometer with dry sliding contact was used to assess Tribological properties [51].

\section{Numerical simulation}

Numerical simulation of $\mu \mathrm{PIM}$ is gaining increased attention for a number of reasons, including the ability to predict optimized process conditions, to estimate processing cycle time and manufacturing bottlenecks [42] and to identify post-processing properties, such as residual stresses, microstructures or dimensional deformation. Therefore, ongoing work in simulation of $\mu$ PIM focuses on simulating the whole process chain including moulding, debinding and sintering [40]. 
Some commercial packages, such as MoldFlow ${ }^{\circledR}$, have already been used for simulating $\mu$ PIM of both micro-parts [49,50,70,71,79] and micro-structured components [49,50]. However, commercially available simulation programs for macroscopic modelling seem to fail when it comes to the prediction of the process in microscopic dimensions [53]. A common drawback in most of the simulation tools is the use of single phase models for the description of the feedstock, which does not allow for the prediction of, e.g., segregation effects [53].

Other limitations of commercial packages include implementing of 2-D modelling rather than 3$\mathrm{D}$, neglecting physical effects, such as surface forces, that are significant on the micro-scale and neglecting significantly high-shear effects observed in micro-cavities. These challenges, in addition to the multi-phase nature of the feedstock, require further development of simulation methods.

A major challenge for commercial simulation packages is the ability to predict powder-binder segregation [128]. Segregation usually happens during the mould-filling stage, and its effect is amplified during the debinding and sintering stages causing a number of quality issues in the final component, such as visual defects, porosity, non-uniform mechanical properties, warpage and cracks [128-131]. Since segregation is usually attributed to high shear rate gradient during injection moulding $[49,128,130]$, this problem is likely to be more dominant during micro-moulding due to high-shear rates associated with flow in micro-scale cavities [132].

Commercial simulation packages, such as SIGMASOFT® [128], are currently being developed for prediction of simulation for conventional PIM. It is, therefore, logical to assume that such packages are not adapted for feedstock performance in $\mu \mathrm{PIM}$, and that includes prediction of segregation.

Some research work is currently directed to developing simulation codes and packages suitable for micro-moulding. PIMSolver® [133], for example, is a package that was used to study $\mu$ PIM of microfluidic substrates. It was shown to slightly over-predicted the filling volume when compared to the experimental result $[42,43,115]$.

Some simulation approaches, such as Dissipative Particle Dynamics (DPD), have been investigated and shown to be able to handle multi-phase systems. The DPD approach describes the form-filling process with respect to the interactions on a mesoscopic scale [53]. The finite element method was implemented to simulate the demoulding process during $\mu \mathrm{PIM}$ and to predict how demoulding forces could be minimized [134]. A constitutive model was developed to predict densification behaviour of microstructured components, taking into consideration variation in grain number during grain growth [135].

Another simulation experiment relied on the DOE approach to investigate a number of process conditions in $\mu \mathrm{PIM}$ of $316 \mathrm{~L}$ : filling time, switch-over point, injection temperature and mould wall temperature $[42,43,115]$. As the part thickness was reduced, process variability increased, and the mould temperature became statistically significant in contributing to over $50 \%$ of the total variability of individual process related parameters. It was also shown that the difference in melt-front temperature was the highest for the lowest thickness, which increased the possibility of residual 
stresses leading to warpage and cracking. The filling time was the major contributor to the maximum shear-rate irrespective of plate thickness [42,43]. The sintering stage in $\mu$ PIM has also been simulated with Abaqus ${ }^{\circledR}$ to estimate shrinkage in 316L specimens [136].

With regard to simulation of feedstock segregation, there is a general agreement that for conventional PIM, simulation tools should be based on multiphase flow models in order to take care of the heterogeneous behaviour of the feedstock and, hence, predict segregation [129,130,137-139]. This is likely to be required for developing simulation packages for $\mu \mathrm{PIM}$, and this is why recent simulation attempts for $\mu$ PIM relied on multiphase flow [68]. In addition to multiphase conditions, such packages should take into consideration physical effects that are usually neglected in conventional packages but are likely to be significant on the micro scale, such as surface tension, wall-slip, capillary forces and micro-scale rheology [140].

More developments are required in simulation of $\mu \mathrm{PIM}$, as existing simulations are not integrated and rely on different simulation platforms, length scales, time scales and material data. They are also not tested against experiments over robust range of conditions [3]. Models for debinding and sintering are also required in order to be able to accurately simulate all the stages of the process chain for $\mu$ PIM.

\section{Variant Processes}

Variant micromoulding processes are currently being developed $\mu \mathrm{PIM}$, were variant processes open up opportunities in functional integration, multi-material components and micro-assembly. Most of reported experiments are limited to micro-parts rather than micro-structured components. For example, two-component $\mu \mathrm{PIM}$ has been achieved by co-injection two different materials $[17,19,41,58,66,70,80,88]$. The process is being developed by adjusting chemical composition and particle size distribution to reach similar shrinkage behaviour.

A similar approach was used to assemble two components by co-injection moulding of two ceramics powders $\left(\mathrm{ZrO}_{2}\right.$ and $\left.\mathrm{Al}_{2} \mathrm{O}_{3}\right)$ [80] and metal (17-4PH) and ceramic $\left(\mathrm{Al}_{2} \mathrm{O}_{3}\right)$ powders [40]. Successful combination of magnetic and non-magnetic materials has also been achieved [1].

Assembling micro-components is also being investigated during the sintering stage $[19,21,80]$. Connection between two 316L stainless steels was achieved during sintering, where two green parts were placed on top of each other and debinded and sintered together [19].

Challenges for multi-component $\mu$ PIM include, firstly, developing a suitable injection moulding process for a well defined interface. Secondly, the sintering process needs to be controlled such that it is suitable for sintering the two different materials simultaneously $[1,141]$.

Another variant process for $\mu \mathrm{PIM}$ is a process that uses plastic sacrificial cores [28]. It has the potential to improve the filling, demoulding and handling, and to produce the tiny parts with threedimensional complex shapes and fine structures [28]. 
In-mould labelling (IML) is another developing variant of $\mu \mathrm{PIM}$, by which colour patterns or lateral structures could be generated on the surface of the $\mu \mathrm{PIM}$ component [17]. This is done by inserting a pre-fabricated foil insert inside the mould and overmoulding them with the feedstock.

\section{Discussion and outlook}

Section 11.1 highlights some of the application areas where $\mu \mathrm{PIM}$ has already been implemented and the market potential of the process. Section 11.2 presents an overall assessment of $\mu \mathrm{PIM}$ as a microfabrication process of micro-components in terms of its main advantages and limitations. Section 11.3 focuses on particular potential development areas of the process chain shown in Figure 1 and suggested research gaps.

\subsection{Applications and market potential}

$\mu \mathrm{PIM}$ has already been used in multiple industrial application areas. These can be classified into five main groupings, as shown in table 5 [1]:

Table 5. Application areas of $\mu$ PIM: Applications that are actually on the market are marked with asterisks

\begin{tabular}{l} 
Application \\
\hline Micromechanical components \\
Custom-designed micromechanical \\
compoenets or replacements for plastic parts \\
to make use of properties of metals or \\
ceramics, such as mechanical strength, \\
corrosion resistance or high temperature \\
performance.
\end{tabular}

Micro-gearbox and stepped-gear wheel structures $[2,13,18,24,31,47]$.

Micro-mould inserts [19,26,55,142].

Electrodes for micro-EDM [19].

Divertors for power applications [73].

* Micro-components for cameras [1], e.g. by Taisei

Kogyo (www.taisei-kogyo.com) in Japan.

* Clock parts, such as operating cams and weights

[143] produced by e.g. Citizen

(www.citizenwatch.com).

* Printer components [143].

\section{Microsystem technologies}

This market segment is dominated by silicon technologies, but there seems to be a portion of this market available for $\mu \mathrm{PIM}$ products as well.
Nozzle structures using ceramic materials [13,18].

Micro-optical benches for communication systems $[13,18]$.

Opto-electronic systems [3].

Data-storage devices [3].

Communication systems [3].

* Automotive systems [3], such as airbag components [143].

\section{Microfluidics and micro-reaction} technologies

High-temperature gas phase reactors or reactors for highly corrosive media [1].

Microfluidic devices for chemical and medical applications, such as micro-mixers and micro-heat exchangers $[2,19,50,82,144]$.

\section{Medical technology} Small replacement bones [1,3].

There is request for biocompatible materials such as ceramics, stainless steel or titanium and reliable manufacturing technologies to
* Micro-needles for selective nerve simulation [24,31].

* Dental instruments and medical biopsy tools $[3,44,78]$. 
produce complex shaped medical

components.
Minimally invasive surgical tools $[3,50]$.

The microstructured surfaces of $\mu$ PIM components are functionalized to react with specific biomolecules [1].

As can be observed form the table, industrial application areas cover all the categories of the micro-components, i.e. micro-parts, micro-structured components and micro-precision components, which indicate the wide capabilities of the $\mu$ PIM. That table shows also that typical application of $\mu \mathrm{PIM}$ components focus on niche areas were other microfabrication processes are not feasible in terms of functional requirements and/or cost.

Turning to future market potential, it should be noted that $\mu \mathrm{PIM}$ is already being used for commercial products, such as those produced by Scholz, who provides solutions for miniaturized plastic gear drivers and micro-technology [1] and Kläger Spritzquss GmbH \& Co who produces ceramic components with complete solutions including mould construction and mould making [1].

Reports suggest that $\mu \mathrm{PIM}$ accesses about $10 \%$ of the microsystem market, because of its competitive costs and ability to form complex shapes [3].

Market expansion of $\mu$ PIM depends on the existence of applications, where other manufacturing techniques cannot satisfy stringent requirements in terms of dimensions or tolerances within massmanufacturing or where they cannot do so as cheaply.

A potential obstacle to the further expansion of $\mu$ PIM components would be the availability of specialized feedstock materials. Considering that material consumption for micro-components is typically small, a case for investment in new feedstock production requires that low volumes of feedstock sales can return that investment.

\subsection{Advantages and limitations of $\mu$ PIM for micro-manufacturing}

Below, a general assessment of the main advantages and limitations of $\mu \mathrm{PIM}$ is presented, drawing on the detailed information of the previous sections throughout this review.

$\mu \mathrm{PIM}$ has a number of advantages as a micro-manufacturing techniques, which include $[13,22,23,29,42]$ :

- Shape complexity (3-D features relative to $2 \frac{1}{2}-\mathrm{D}$ features typical to silicon techniques) [3] and accurate replication of microstructures [2].

- Net-shape or near net-shape forming. PIM in general offers high material utilisation, where probably $97 \%$ of the powder is delivered in final components $[14,20,35,88]$.

- $\mu \mathrm{PIM}$ is applicable to several material functional classes. These include materials for magnetic, mechanical or electric properties, as well as for high wear resistances $[7,10,43,47,57,60,145]$.

- $\mu \mathrm{PIM}$ increases the range of materials that can be used for microsystem applications, in comparison with other techniques, such as micro cutting, laser ablation, silicon etching or LIGA 
technique, which are often limited in respect to processible materials and/or to series production $[5,13,19]$.

- $\mu \mathrm{PIM}$ is cost-effective for mass production relative to other micro-manufacturing techniques, such as micro-cutting, laser ablation, silicon etching and LIGA [1,2,19,31].

- For small series and prototyping, low-pressure PIM (L-PIM) can be implemented, where pressure values are limited to 0.1 to $1 \mathrm{MPa}$, and low-viscosity paraffin or wax is used instead of a highviscosity polymeric binder [54,70].

- A considerable amount of know-how is already available from established PIM techniques [7,12].

On the other hand, $\mu$ PIM has also a number of limitations that need to be addressed:

- Available commercial feedstocks are limited in powders with fine size distribution (particle size less than $5 \mu \mathrm{m})[19,22,31]$.

- The minimum feature size and surface roughness are limited relative to other micro-fabrication techniques due to powder grain size (more details in following sections) [59].

- Relatively high investment costs are usually required, especially for mould fabrication.

- Shape distortion and shrinkage due to debinding and sintering affect dimensional tolerances [59].

- The mechanical properties may suffer from the presence of pores or due to excessive grain growth during sintering [59].

- Cycle time is relatively long due to time consumed for debinding and sintering.

- When replicating micro-parts, a significant amount of feedstock could be scrapped as the size of the runner system become large relative to the part size.

Section 11.3 presents a more detailed assessment of the process by presenting a brief evaluation of each of the process chain stages and possible areas of improvement.

\subsection{Challenges and research gaps}

In spite of the significant developments introduced into the field during the past decade, a number of challenges in different aspects of the process chain need to be addressed. This would enable the expansion of market applications of $\mu \mathrm{PIM}$ in producing ceramic and metallic micro-components, and it would make transferring production from current manufacturing techniques to $\mu \mathrm{PIM}$ increasingly economically feasible.

11.3.1. Designing for $\mu$ PIM. A fundamental requirement for manufacturability by $\mu \mathrm{PIM}$ is the ability to design the required part taking into consideration the advantages and limitations of the process. Designing for $\mu \mathrm{PIM}$ has not been discussed enough in literature, because the majority of experiments focus on producing relatively simple structures, basically $2 \frac{1}{2} 2$-D geometries, for prototyping purposes 
or proof of concept. Most of the demonstrated examples belong, therefore, to the category of microstructured components rather than micro-parts.

In terms of geometrical limitations, it seems safe to assume that $\mu \mathrm{PIM}$ follows the same design rules for well established conventional injection moulding processes, such as mouldability and demouldability requirements in terms of draft angles, undercuts and uniform cross sections. However, designing for $\mu \mathrm{PIM}$ should take into consideration minimum mouldable dimensions and achievable aspect ratios, which are also limited by the powder size. In addition, sources of dimensional deformation, such as densification and volume shrinkage of sintered parts affect the overall quality of the part.

The relation of these design considerations to factors including particle size, feedstock rheology and processing parameters is yet to be fully understood. Design rules need to be developed for $\mu$ PIM in order to enable designers and engineers evaluate the feasibility of implementing $\mu$ PIM for their specific component.

11.3.2. Feedstock systems. A number of metals and ceramics have successfully been implemented in $\mu$ PIM. $\mu$ PIM experiments were initially conducted using commercial feedstock developed for conventional PIM. However, it became apparent that specialized feedstock systems would be necessary for $\mu$ PIM due to the physical scale of the process.

There is a general agreement among researchers that decreasing the particle size is becoming a necessity for successful expansion of the $\mu \mathrm{PIM}$ technology. Sub-micron powders and nanopowders seems a natural option for $\mu \mathrm{PIM}$ to extend the range of achievable minimum dimensions and maximum aspect ratios. Decreasing the particle size would also allow for better control of surface properties that are a significant consideration on the micro-scale, for example for microfluidic applications.

Decreasing the powder size, on the other hand, would require a compromise between feedstock composition and flow properties. Tailor-made feedstock for $\mu$ PIM should take into consideration the rheological performance of the feedstock melt during injection moulding to ensure complete filling of micro-features and, hence, accurate dimensional replication.

In addition to powder size, the range of available metals and ceramics needs to be expanded beyond the current available selection. Microsystem applications usually require specialized material properties in terms of, for example, biocompatibility or magnetic properties. Such requirements should be considered when developing feedstock for $\mu \mathrm{PIM}$.

Some other issues that need to be investigated with $\mu$ PIM feedstock includes powder-binder separation during moulding, and the need for standardized databases of $\mu \mathrm{PIM}$ material properties, which can be implemented in numerical simulations [3]. 
11.3.3. Mould fabrication. Mould fabrication techniques have developed significantly during the past years through the introduction of novel micro-fabrication technologies. Micro-structured mould inserts are already being produced for $\mu \mathrm{IM}$ and $\mu \mathrm{HE}$ of polymers on a commercial scale.

Each micro-fabrication technique has limitations in terms of material, dimensions, roughness and aspect ratio, which puts some limitations on the mould manufacturing route for a specific component. This has been tackled by adopting hybrid manufacturing routes, where more than one manufacturing method are implemented to produce the mould inserts.

Variothermal moulds have been successfully implemented in $\mu$ PIM to achieve complete filling. Specialized moulds are also being developed for multi-material injection moulding by $\mu$ PIM and moulding of geometrically complex shapes.

Some research areas need further investigation, such as the effect of the surface properties of the mould on the surface properties of the sintered component. Another issue is how to assess the life expectancy of the mould insert relative to the feedstock material and the number of cycles in a massfabrication environment.

11.3.4. Injection moulding. Very little is discussed in the literature about the effect of the injection moulding step on part quality. Reported data are usually specific for a particular $\mu$ PIM application and thorough understanding of the process is not usually presented.

The relationship between process parameters and part quality in terms of, for example, dimensions, part weight, surface finish, process variability and generation of weld lines is still to be investigated for $\mu \mathrm{PIM}$. In addition, the effect of the feedstock composition, rheological performance and process parameters have not been given enough attention in the literature.

11.3.5. Debinding. Several debinding techniques have been developed for different types of feedstock systems. Thermal debinding is widely used for $\mu$ PIM applications followed by catalytic debinding. The latter produces more accurate tolerances and shape retention, but it requires specialized ovens equipped for handling concentrated acids and toxic gases.

The relation between debinding parameters/schedules and part quality needs further investigation. Relevant issues include the handling of nanoscale pores and particle contamination produced during debinding [3].

11.3.6. Sintering. Research in sintering $\mu \mathrm{PIM}$ components has focused on densification, porosity, dimensional deformation and surface finish. Models are currently being developed to predict graingrowth during $\mu \mathrm{PIM}$ sintering. This included the effect of process conditions on the generation of dense layers and the overall surface properties of sintered components. 
Surface roughness values of a few hundred nanometres have been reached in $\mu$ PIM. Research has focused on understanding the effect of process condition on sintered part quality, but reliable qualitative data are still missing, and this area needs further investigation.

11.3.7. Testing and inspection. Standard testing and inspection techniques have been used to assess the quality of $\mu$ PIM components. Most of the used techniques rely on optical systems, which are useful for visualisation purposes but limited in terms of measurement capabilities. A significant challenge in testing and inspection arises because most measuring systems are not suitable for parts of the size produced by $\mu \mathrm{PIM}$, and standard measurement procedures are yet to be defined [37].

Reliable quality control of micro-components would require the development of specialized equipment to evaluate party quality in terms of dimensions or part weight. Micro-coordinate measurement machines ( $\mu$-CMM), for example, have been used in $\mu \mathrm{IM}$ of polymers for relatively accurate dimensional measurements, and may also be a viable option for $\mu$ PIM components.

There is a need for automated testing and inspection techniques, and a public repository is needed for the properties of common materials processed by $\mu$ PIM techniques [3].

11.3.8. Simulation. Some simulation experiments have been demonstrated for $\mu$ PIM applications. Those using commercial simulation packages show that they tend to over-predict filling in $\mu$ PIM. Simulation on the micro-scale needs to take into consideration the effect of, for example, surface forces, surface-to-volume ratio and other relevant size issues. Powder-binder segregation is also an important issue that is not fully address in simulation packages for $\mu$ PIM.

Models are currently being developed to account for different stages of the $\mu$ PIM process chain. This topic is still being investigated, since no effective model is currently reliable for $\mu$ PIM. The lack of standardized material properties also presents a challenge for the development of reliable simulation programs that take into consideration multi-phase flow on the micro-scale.

11.3.9. Variant processes. Extending the capabilities of the current $\mu \mathrm{PIM}$ process beyond its limitations would enable new applications. The increasing complexity of current microsystem technologies poses more demands in terms of functionality integration, multi-material structures and 3-D complex geometries.

Variant processes, already showing success in $\mu \mathrm{IM}$, are likely to expand the range of $\mu \mathrm{PIM}$ capabilities. 2-component moulding, micro-overmoulding, lost-core technology and similar variants are examples of potential research areas that would enable combining structural complexity with the high-volume capabilities of $\mu$ PIM. 


\section{Conclusion}

This paper aimed at assessing $\mu \mathrm{PIM}$ as a microfabrication technology taking into consideration recent development and state-of-the-art technology. The reviewed research activities illustrate an increasing implementation of the process in different areas including commercial products.

A number of challenges, however, need to be addressed in order to improve confidence in the economic feasibility of changing to $\mu \mathrm{PIM}$ from another manufacturing technology or justifying basing a new process on $\mu \mathrm{PIM}$.

Design rules and considerations, feedstock range and particle size, injection moulding control and optimisation, debinding and sintering parameters are key areas of investigation. In addition, specialized inspection techniques and reliable simulation models are necessary for quality control considerations. Finally, expanding the capabilities of $\mu$ PIM by investigating variant processes would be important for meeting increasing demands of the microsystems market in terms of functional integration and structural complexity.

Addressing the above issues in addition to finding new microsystem applications for $\mu$ PIM would create a market demand for the technology helping it to evolve into a well-established, highvolume micro-manufacturing method.

\section{References}

[1] Petzoldt F 2008 Micro powder injection moulding - challenges and opportunities Powder Injection Moulding Int. 2 37-42

[2] Yin H, Jia C and Qu X 2008 Micro powder injection molding - large scale production technology for micro-sized components. Sci. China Ser. E Technol. Sci. 51 121-6

[3] German R M 2009 Medical and dental applications for microminiature powder injection moulding (microPIM) - a roadmap for growth PIM Int. 3 21-9

[4] Piotter V, Hanemann T, Ruprecht R and Haußelt J 1997 Injection molding and related techniques for fabrication of microstructures Microsyst. Technol. 3 129-33

[5] Ruprecht R, et al. 1997 Various replication techniques for manufacturing three-dimensional metal microstructures. Microsyst. Technol. 4 28-31

[6] Piotter V, Benzler T, Ruprecht R and Haußelt J 1998 Manufacturing of micro sized structures by MIM and CIM Int. Conf. on Powder Metallurgy \& Particulate Materials pp 5-161 - 5-169

[7] Piotter V 1999 PIM looks for role in the micro world Met. Powder Rep. 54 36-9

[8] Shimizu T, Murakoshi Y, Wang Z, Maeda R and Sano T 1999 Microfabrication techniques for thick structure of metals and PZT Proc. SPIE Int. Soc. Opt. Eng. (30 March through 1 April 1999) pp $472-7$

[9] Benzler T, Piotter V, Hanemann T, Mueller K, Norajitra P, Ruprecht R and Hausselt J 1999 Innovations in molding technologies for microfabrication Proc. of the 1999 Micromachining and 
Microfabrication Process Technology V (20 September - 22 September 1999) Bellingham, WA, United States.

[10] Tay B Y, Liu L, Loh N H, Tor SB, Murakoshi Y and Maeda R 2005 Surface roughness of microstructured component fabricated by $\mu$ MIM Mater. Sci. Eng. A 396 311-9

[11] Attia U M, Marson S and Alcock J R 2009 Micro-injection moulding of polymer microfluidic devices Microfluid. Nanofluid. 7 1-28

[12] Liu L, Loh N H, Tay BY, Tor S B, Murakoshi Y and Maeda R 2007 Effects of thermal debinding on surface roughness in micro powder injection molding Mater. Lett. 61 809-12

[13] Ruprecht R, Gietzelt T, Müller K, Piotter V and Haußelt J 2002 Injection molding of microstructured components from plastics, metals and ceramics Microsyst. Technol. 8 351-8

[14] German R M 1999 A rationalization of the powder injection molding process for stainless steels based on component feature Int. Conf. and Exhib. on Powder Metallurgy and Particulate Materials (31 May-4 June 1999) pp 5.71 - 5.83

[15] Attia U M 2009 Micro-injection moulding of three-dimensional integrated microfluidic devices PhD Thesis. Cranfield University, 2009

[16] Loh N H, Tor SB, Tay B Y, Murakoshi Y and Maeda R 2003 Micro powder injection molding of metal microstructures Mater. Sci. Forum 426-432 4289-94

[17] Piotter V, Plewa K, Mueller T, Ruh A, Vorster E, Ritzhaupt-Kleissl H-J and Hausselt J 2010 Manufacturing of high-grade micro components by powder injection molding Key. Eng. Mat. 447-448 $351-5$

[18] Piotter V, Gietzelt T, Plewa K, Ruprecht R and Hausselt J 2001 Tiny parts made by micro powder injection molding Proc. Adv. Powder. Metall. Part. Mater. (13-17 May 2001) pp 728-36

[19] Rota, A 2002 New features in material issues for metallic micro components by MIM Proc. PM2TEC pp 10/49 - 10/57

[20] Rota A, Duong T V and Hartwig T 2002 Micro powder metallurgy for the replicative production of metallic microstructures. Microsyst. Technol. 8 323-5

[21] Rota A, Imgrund P and Petzoldt F 2004 Fine powders give micro producers the cutting edge Metal Powder Report 59 14-7

[22] Tay B Y, Liu L, Loh N H, Tor S B, Murakoshi Y and Maeda R 2005 Injection molding of 3D microstructures by $\mu$ PIM Microsyst. Technol. 200511 210-3

[23] Fu G, Loh N H, Tor S B, Murakoshi Y and Maeda R 2005 Effects of injection molding parameters on the production of microstructures by micropowder injection molding Mater. Manuf. Process. 20 977-85

[24] Li SG, Fu G, Reading I, Tor SB, Loh N H, Chaturvedi P, Yoon S F and Youcef-Toumi K 2007 Dimensional variation in production of high-aspect-ratio micro-pillars array by micro powder injection molding. Appl. Phys. A $\mathbf{8 9}$ 721-8 
[25] Liu L, Loh N H, Tay B Y, Tor S B, Murakoshi Y and Maeda R 2006 Micro powder injection molding: Sintering kinetics of microstructured components Scripta. Mater. 55 1103-6

[26] Fu G, Tor SB, Loh N H, Hardt D E 2010 Fabrication of robust tooling for mass production of polymeric microfluidic devices J. Micromech. Microengineering 20 Article no. 085019

[27] Liu L, Loh N H, Tay B Y, Tor S B, Murakoshi Y and Maeda R 2006 Densification and grain growth of stainless steel microsize structures fabricated by $\mu$ MIM Applied Physics A: Materials Science and Processing 200683 31-6

[28] Nishiyabu K, Kanoko Yand Tanaka S 2007 Innovations in micro metal injection molding process by lost form technology Mater. Sci. Forum 534-536 369-72

[29] Tay B Y, Liu L, Loh N H, Tor S B, Murakoshi Y and Maeda R 2006 Characterization of metallic micro rod arrays fabricated by $\mu$ MIM Mater. Charact. 57 80-5

[30] Fu G, Tor S, Loh N, Tay B and Hardt D E 2007 A micro powder injection molding apparatus for high aspect ratio metal micro-structure production J. Micromech. Microengineering 17 1803-9

[31] Fu G, Loh N H, Tor S B, Tay B Y, Murakoshi Y and Maeda R 2005 Injection molding, debinding and sintering of 316L stainless steel microstructures Appl. Phys. A 81 495-500

[32] Fu G, Loh N H, Tor S B, Murakoshi Y and Maeda R 2004 Replication of metal microstructures by micro powder injection molding Mater. Des. 25 729-33

[33] Liu Z Y, Loh N H, Tor S B, Khor K A, Murakoshi Y, Maeda R and Shimizu T 2002 Micropowder injection molding J. Mater. Process. Technol. 127 165-8

[34] Liu Z Y, Loh N H, Tor S B, Khor K A, Murakoshi Y and Maeda R 2001 Binder system for micropowder injection molding Mater. Lett. 48 31-8

[35] Okubo K, Tanaka S, Ito H 2009 The effects of metal particle size and distributions on dimensional accuracy for micro parts in micro metal injection molding Proc. of the Annual Technical Conf., (ANTEC 2009); (22-24 June 2009) pp 2592-7

[36] Haupt U 2009 High precision: micro injection moulding with powder materials CFI Ceramic Forum International 86 E25-E28

[37] Rota A, Imgrund P, Kramer L, Meyer R and Haack J 2005 Micro metal injection moulding Quality assurance in series production Proc. Euro PM pp 377-82

[38] Checot-Moinard D, Rigollet C and Lourdin P 2010 Powder injection moulding PIM of feedstock based on hydrosoluble binder and submicronic powder to manufacture parts having micro-details. Powder Technol. In Press DOI: 10.1016/j.powtec.2010.08.045

[39] Müller T, Piotter V, Plewa K, Guttmann M, Ritzhaupt-Kleissl H-J and Hausselt J 2009 Ceramic micro parts produced by micro injection molding: latest developments Microsyst. Technol. 16 14191423

[40] Piotter V, Finnah G, Zeep B, Ruprecht R and Hausselt J 2007 Metal and ceramic micro components made by powder injection molding Mater. Sci. Forum 534-536 373-6 
[41] Piotter V, Mueller T, Plewa K, Ritzhaupt-Kleissl H-J, Ruh A and Hausselt J 2010 One- and twocomponent micro powder injection moulding derived from thermoplastic microreplication Plast. Rubber Compos. 39 287-92

[42] Urval R, Wu C, Atre S V, Park S-J and German R M 2007 CAE-based process design of PIM for microfluidic device components Powder Injection Moulding Int. 7-12

[43] Urval R, Lee S, Atre SV, Park S-J, German RM 2008 Optimisation of process conditions in powder injection moulding of microsystem components using a robust design method: Part I. Primary design parameters Powder Metall. 51 133-42

[44] German R M 2010 Materials for microminiature powder injection molded medical and dental devices Int. J. Powder Metall. 46 15-8

[45] Nishiyabu K, Andrews I and Tanaka S 2009 Making and measuring in micro MIM manufacturing Met. Powder Rep. 64 22-5

[46] Piotter V, Benzler T, Gietzelt T, Ruprecht R and Haußelt J 2000 Micro powder injection molding Adv. Eng. Mater. 2 639-42

[47] Loh N H, Tor S B, Tay B Y, Murakoshi Y and Maeda R 2008 Fabrication of micro gear by micro powder injection molding Microsyst. Technol. 14 43-50

[48] Osada T and Miura H 2010 Nitriding response of microminiature powder injection molded titanium Int. J. Powder Metall. 46 39-44

[49] Wu C, Atre S V and Park S-J 2006 Material homogeneity in ceramic micro arrays fabricated by powder injection molding Proc. IIE Annu. Conf. Exhib.; (20-24 May 2006)

[50] Laddha S G, Wu C, Park S-J, Lee S, Ahn S, German RM and Atre S V 2010 Characterization and simulation of macroscale mold-filling defects in microminiature powder injection molding International Journal of Powder Metallurgy 46 49-60

[51] Meng J, Loh N H, Tay B Y, Fu G and Tor S B 2010 Tribological behavior of 316L stainless steel fabricated by micro powder injection molding Wear 286 1013-9

[52] Salk N, Seemann T, Rota A, Schlüter M, Hoffmann M and Harms C 2007 New functions for microfluidic components by using micro metal injection molding ( $\mu$-MIM) Chem. Eng. Commun. 194 $859-66$

[53] Heldele R, Schulz M, Kauzlaric D, Korvink J G and Haußelt J 2006 Micro powder injection molding: process characterization and modeling Microsyst. Technol. 12 941-6

[54] Rak Z S 1999 New trends in powder injection moulding Powder Metall. Met. Ceram. 38 126-32

[55] Rota A, Duong T-V, Hartwig T 2002 Wear resistant tools for reproduction technologies produced by micro powder metallurgy Microsyst. Technol. 7 225-8

[56] Attia U M and Alcock J R 2010 Evaluating and controlling process variability in micro-injection moulding Int. J. Adv. Manuf. Technol. In press; DOI: 10.1007/s00170-010-2724-1 
[57] Mohamad Nor N H, Muhamad N, Ismail M H, Jamaludin K R, Ahmad S and Ibrahim M H I 2009 Flow behaviour to determine the defects of green part in metal injection molding Int. J. Mech. Mater. Eng. 4 70-5

[58] Imgrund P, Rota A and Simchi A 2008 Microinjection moulding of 316L/17-4PH and 316L/Fe powders for fabrication of magnetic-nonmagnetic bimetals J. Mater. Process. Technol. 200 259-64

[59] Garino T J, Morales A M and Boyce B L 2004 The mechanical properties, dimensional tolerance and microstructural characterization of micro-molded ceramic and metal components Microsyst. Technol. 10 506-9

[60] Zauner R 2006 Micro powder injection moulding Microelectron. Eng. 83 1442-4

[61] Imgrund P, Rota A, Kramer L and Krämer S 2007 Metal injection moulding at micro scale Kunsts. Int. 97 7-10

[62] Baek E R, Supriadi S, Choi C-J, Lee B-T and Lee J-W 2007 Effect of particle size in feedstock properties in micro powder injection molding Mater. Sci. Forum 534-536 349-52

[63] Supriadi S, Baek E R, Choi C J and Lee B T 2007 Binder system for STS 316 nanopowder feedstocks in micro-metal injection molding J. Mater. Process. Technol. 187-188 270-3

[64] Liu L, Loh N H, Tay B Y, Tor S B, Murakoshi Y and Maeda R 2005 Mixing and characterisation of 316L stainless steel feedstock for micro powder injection molding Mater. Charact. 54 230-8

[65] Liu L, Loh N H, Tay B Y and Tor S B 2010 Microstructure evolution of 316L stainless steel micro components prepared by micro powder injection molding Powder Technol. In press; DOI: 10.1016/j.powtec.2010.09.027

[66] Liu L, Loh N H, Tay B Y, Tor S B, Yin H Q and Qu X H 2010 Investigation of final-stage sintering of various microsize structures prepared by micro powder injection molding Appl. Phys. A In press

[67] Quinard C, Barriere T and Gelin J C 2009 Development and property identification of 316L stainless steel feedstock for PIM and $\mu$ PIM Powder Technol. 190 123-8

[68] Quinard C, Barrière T and Gelin J C 2008 Experiments and identification in micro powder injection moulding from stainless steel powder $5 \mu \mathrm{m}$ size Int. J. Mater. Form. 1 25-8

[69] Ibrahim M H I, Muhamad N and Sulong A B 2009 Rheological investigation of water atomised stainless steel powder for micro metal injection molding Int. J. Mech. Mater. Eng. 4 1-8

[70] Piotter V, Hanemann T, Heldele R, Mueller M, Mueller T, Plewa K and Ruh A 2010 Metal and ceramic parts fabricated by microminiature powder injection molding Int. J. Powder Metall. 46 21-8

[71] Mueller T, Piotter V, Plewa K, Prokop J, Ritzhaupt-Kleissl H and Hausselt J 2009 Complex shaped micro components produced by powder injection molding Proc. 4M/ICOMM 2009 - The Global Conference on Micro Manufacture pp 103-6

[72] Nishiyabu K and Tanaka S 2009 Accuracy evaluation on SUS ultra-compact module $0.07 \mathrm{~mm}$ gears manufactured by MIM Funtai Oyobi Fummatsu Yakin/Journal of the Japan Society of Powder and Powder Metallurgy 56 268-73 
[73] Zeep B, Norajitra P, Piotter V, Boehm J, Ruprecht R and Hausselt J 2007 Net shaping of tungsten components by micro powder injection moulding Fusion Eng. Des. 82 2660-5

[74] Schmidt H, Rota AC, Imgrund P and Leers M 2009 Micro metal injection moulding for thermal management applications using ultrafine powders PIM Int. 3 54-8

[75] Nishiyabu K, Kakishita K and Tanaka S 2007 Micro metal injection molding using hybrid micro/nano powders Mater. Sci. Forum 534-536 381-4

[76] Nishiyabu K, Matsuzaki S and Tanaka S 2009 Advanced metal powder injection moulding for multilayered micro porous titanium components PIM Int. 3 60-3

[77] Meng J, Loh N H, Tay B Y, Tor S B, Fu G, Khor K A and Yu L 2011 Pressureless spark plasma sintering of alumina micro-channel part produced by micro powder injection molding Scripta Mater. $64237-40$

[78] Thomas P, Levenfeld B, Várez A and Cervera A 2009 Production of Alumina Microparts by Powder Injection Molding. Int. J. of App. Ceramic Technol. DOI: 10.1111/j.1744-7402.2009.02471.x [79] Laddha S, Wu C, Vallury S, Lingam G, Lee S, Simmons K, Thomas P, Levenfeld B, Várez A, Park S-J, Ahn S, German R M and Atre S V 2009 Characterisation of alumina feedstock with polyacetal and wax-polymer binder systems for micro powder injection moulding PIM Int. 3 64-70

[80] Ruh A, Dieckmann A-M, Heldele R, Piotter V, Ruprecht R, Munzinger C, Fleischer J and Haußelt J 2008 Production of two-material micro-assemblies by two-component powder injection molding and sinter-joining Microsyst. Technol. 14 1805-11

[81] Piotter V, Mueller T, Plewa K, Prokop J, Ritzhaupt-Kleissl H-J and Hausselt J. 2010 Manufacturing of complex-shaped ceramic components by micropowder injection molding. Int. J. Adv. Manuf. Technol. 46 131-4

[82] Wang M-W 2010 Microceramic injection molding of a multilayer micropatterned micropart Int. J. Adv. Manuf. Technol. In press; DOI: 10.1007/s00170-010-2597-3

[83] Yu P, Li Q, Fuh J, Li T and Ho P 2009 Micro injection molding of micro gear using nano-sized zirconia powder Microsyst. Technol. 15 401-6

[84] Petronis S, Eckert K-L, Gold J and Wintermantel E 2001 Microstructuring ceramic scaffolds for hepatocyte cell culture J. Mater. Sci. Mater. Med. 12 523-8

[85] Merz L, Rath S, Piotter V, Ruprecht R, Ritzhaupt-Kleissl J and Hausselt J 2002 Feedstock development for micro powder injection molding Microsyst. Technol. 8 129-32

[86] Piotter V, Finnah G, Oerlygsson G, Ruprecht R and Haußelt J 2005 Special variants and simulation of micro injection moulding Proc. Injection Moulding 2005: Collected Papers of the 5th Int. Conf., (Copenhagen, Denmark; March 1-2)

[87] Okubo K, Tanaka S and Ito H 2010 The effects of metal particle size and distributions on dimensional accuracy for micro parts in micro metal injection molding Microsyst. Technol. 16 203741 
[88] Piotter V, Beck M, Plewa K, Ritzhaupt-Kleissl H, Ruh A and Hausselt J 2009 Micro PIM moves into the zone of industrial possibility Metal Powder Report 64 35-7

[89] Kim S-W, Suk M-J, Kim Y-D and Moon I-H 2005 Micro Metal Powder Injection Molding of WCu Nanocomposite Powder Met. Mater. Int. 11 205-8

[90] Gietzelt T, Jacobi O, Piotter V, Ruprecht R and Hausselt J 2004 Development of a micro annular gear pump by micro powder injection molding J. Mater. Sci. 39 2113-9

[91] Nishiyabu K, Matsuzaki S and Tanaka S 2007 Net-shape manufacturing of micro porous metal components by powder injection molding Mater. Sci. Forum 534-536 981-4

[92] German R M and Bose A 1997 Injection molding of metals and ceramics (Princeton, N.J.: Metal Powder Industries Federation)

[93] Vieira MT, Martins AG, Barreiros FM, Matos M and Castanho JM 2008 Surface modification of stainless steel powders for microfabrication J. Mater. Process. Technol. 201 651-6

[94] Bissacco G, Hansen HN, Tang T and Fugl J 2005 Precision manufacturing methods of inserts for injection molding of microfluidic systems Proc. ASPE Spring Topical Meeting on Precision Mecro/Nano Scale Polymer Based Component \& Device Fabrication; April 2005

[95] Uriarte L, Ivanov A, Oosterling H, Staemmler L, Tang P T and Allen D 2005 A comparison between microfabrication technologies for metal tooling. Proc. of the 1st Int. Conf. 4M 2005 pp 351-4 [96] Madou M J 2001 Fundamentals of microfabrication : the science of miniaturization 2nd ed (Boca Raton, FL: CRC Press)

[97] De Grave A and Brissaud D 2005 Collaboration and integration in the design of microelectromechanical systems (MEMS) CIRP Design Conf. 2005

[98] Stokes C and Palmer P J 2006 3D micro-fabrication processes: a review. Institution of Engineering and Technology Seminar on MEMS Sensors and Actuators, ICEPT; 27-28 April 2006 [99] Henann DL, Srivastava V, Taylor HK, Hale MR, Hardt DE and Anand L 2009 Metallic glasses: Viable tool materials for the production of surface microstructures in amorphous polymers by microhot-embossing J. Micromech. Microengineering 19 Article number 115030

[100] Fu G, Loh N H, Tor SB, Tay B Y, Murakoshi Y and Maeda R 2005 A variotherm mold for micro metal injection molding Microsyst. Technol. 11 1267-71

[101] Cheng C-C, Ono Y, Whiteside B D, Brown E C, Jen C-K and Coates PD 2007 Real-time diagnosis of micro powder injection molding using integrated ultrasonic sensors Int. Polym. Process. 22 140-5

[102] Schneider J, Kienzler A, Deuchert M, Schulze V, Kotschenreuther J, Zum Gahr K-H, Löhe D and Fleischer J 2008 Mechanical structuring, surface treatment and tribological characterization of steel mould inserts for micro powder injection moulding Microsyst. Technol. 14 1797-803

[103] Saha B, Liu E, Tor S B, Khun N W, Hardt D E and Chun J H 2009 Anti-sticking behavior of DLC-coated silicon micro-molds J. Micromech. Microengineering 19 Article number 105025 
[104] Saha B, Liu E, Tor S B, Khun N W, Hardt D E and Chun J H 2010 Replication performance of Si-N-DLC-coated Si micro-molds in micro-hot-embossing J. Micromech. Microengineering 20 Article number 045007

[105] Saha B, Liu E, Tor S B, Hardt D E, Chun J H and Khun N W 2010 Improvement in lifetime and replication quality of Si micromold using N:DLC:Ni coatings for microfluidic devices Sens. Actuators. B Chem. 150 174-82

[106] Schneider J, Iwanek H, Zum Gahr K-H 2005 Wear behaviour of mould inserts used in micro powder injection moulding of ceramics and metals Wear 259 1290-8

[107] Fleischer J, Buchholz C, Weule H 2003 Automation of the powder-injection-moulding process for micro-mechanical parts CIRP Annals - Manufacturing Technology 52 419-22

[108] Fleischer J, Dieckmann A-M 2006 Automation of the powder injection molding process Microsyst. Technol. 12 702-6

[109] Osswald T A, Turng L-S and Gramann PJ (Eds) 2001 Injection molding handbook (Cincinnti, OH: Hanser/Gardner Publications)

[110] Rosato D V, Rosato D V and Rosato MG (Eds) 2001 Injection molding handbook 3rd ed (Boston: Kluwer Academic)

[111] Giboz J, Copponnex T and Mélé P 2007 Microinjection molding of thermoplastic polymers: a review J. Micromech. Microengineering 17 R96-R109

[112] Yao D and Kim B 2002 Injection molding high aspect ratio microfeatures J. Inject. Molding Technol. 6 11-7

[113] Attia U M, Alcock J R 2009 An evaluation of process-parameter and part-geometry effects on the quality of filling in micro-injection moulding Microsyst. Technol. 15 1861-72

[114] Attia U M and Alcock J R 2010 Optimising process conditions for multiple quality criteria in micro-injection moulding Int. J. Adv. Manuf. Technol. 50 533-542

[115] Urval R, Lee S, Atre SV, Park S-J, German RM 2010 Optimisation of process conditions in powder injection moulding of microsystem components using robust design method Part 2 Secondary design parameters Powder Metall. 53 71-81

[116] Ebenhoech J, Ter Maat J and Sterzel H J 1991 Catalytic gas phase erosion. A new technique for quick debinding of injection molded green parts Proc. of the 1991 Powder Metallurgy Conf. and Exhibition; (9-12 June 1991)

[117] Sterzel H, Ter Maat and Johan H H 1993 Thermoplastic compositions for producing metallic moldings United States patent 5198489. 1993 03/30/1993

[118] Ebenhoech J, Weinand D, Kochanek W and Bloemacher M 1994 Thermoplastic compositions for producing metallic moldings United States patent 5362791. 1994 11/08/1994

[119] Bloemacher M and Weinand D 1997 Catamold - a new direction for powder injection molding J. Mater. Process. Technol. 63 918-22 
[120] Shimizu T, Murakoshi Y, Sano T, Maeda R and Sugiyama S 1998 Fabrication of micro-parts by high aspect ratio structuring and metal injection molding using the supercritical debinding method Microsyst. Technol. 5 90-2

[121] Li W-B, Ashby MF, Easterling KE 1987 On densification and shape change during hot isostatic pressing. Acta Metallurgica 35 2831-42

[122] German R M 2005 Powder metallurgy and particulate materals processing: the processes, materials, products, properties and applications (Princeton, N.J.: Metal Powder Industries Federation) [123] ASTM International 2004 ASTM E112 - 96(2004)e2: Standard Test Methods for Determining Average Grain Size.

[124] Auhorn M, Beck T, Schulze V and Löhe D 2002 Quasi-static and cyclic testing of specimens with high aspect ratios produced by micro-casting and micro-powder-injection-moulding Microsyst. Technol. 8 109-12

[125] Kasanická B, Wroblewski T, Schulze V and Löhe D 2005 Analysis of residual stresses in micro powder injection moulded micro bending specimens made of zirconia Mater. Sci. Forum 490-491 503-8

[126] Auhorn M, Kasanická B, Beck T, Schulze V and Löhe D 2003 Microstructure, surface topography and mechanical properties of slip cast and powder injection moulded microspecimens made of zirconia Zeitschrift fuer Metallkunde/Materials Research and Advanced Techniques 4 599605

[127] Auhorn M, Beck T, Schulze V, Löhe D 2004 Determination of mechanical properties of slip cast, micro powder injection moulded and microcast high aspect ratio microspecimens Microsyst. Technol. 10 489-92

[128] Thornagel M 2010 Simulating flow can help avoid mould mistakes Met. Powder Rep. 65 26-9

[129] Barriere T, Liu B and Gelin J C 2002 Analyses of powder segregation in MIM Met. Powder. Rep. 57 30-3

[130] Ilinca F, Hétu J-F 2008 Three-dimensional free surface flow simulation of segregating dense suspensions Int. J. Numer. Methods Fluids 58 451-72

[131] Ilinca F, Hétu J-F Three-dimensional numerical simulation of segregation in powder injection molding Int. Polym. Process. 23 208-15

[132] Heldele R, Rath S, Merz L, Butzbach R, Hagelstein M and Haußelt J 2006 X-ray tomography of powder injection moulded micro parts using synchrotron radiation Nucl. Instrum. Methods Phys. Res.

Sect. B 246 211-6

[133] CetaTech. PIMsolver Available at:

http://www.cetatech.com/english/sub_03/index.php?a_page=3\&b_page=4. Accessed 2010.

[134] Fu G, Tor S B, Loh N H, Tay B Y and Hardt D E 2008 The demolding of powder injection molded micro-structures: Analysis, simulation and experiment J. Micromech. Microengineering 18 Article number 075024 
[135] Liu L, Loh NH, Tay BY, Tor SB, Murakoshi Y and Maeda R 2008 Constitutive modelling of microstructured components fabricated by micro powder injection molding Acta. Mater. 56 5560-6 [136] Kong X, Quinard C, Barriere T and Gelin J-C 2010 Micro powder injection moulding of 316L stainless steel feedstock and numerical simulation of the sintering stage Proc. 10th Int. Conf. on Numerical Methods in Industrial Forming Processes (NUMIFORM 2010); (13-17 June 2010)

[137] Barrière T, Gelin JC and Liu B 2002 Improving mould design and injection parameters in metal injection moulding by accurate 3D finite element simulation J. Mater. Process. Technol. 125-126 51824

[138] Samanta SK, Chattopadhyay H, Pustal B, Berger R, Godkhindi MM and Bührig-Polaczek A 2008 A numerical study of solidification in powder injection molding process Int. J. Heat Mass Transf. $51672-82$

[139] Barriere T, Gelin JC and Liu B 2001 Experimental and numerical investigations on properties and quality of parts produced by MIM Powder Metall. 44 228-34

[140] Baltes B, Fedder H and Korvink T (eds.) 2005 Microengineering of metals and ceramics. Part 1: design, tooling and injection molding - Chapter 3: Modeling Micro PIM (Weinheim; Chichester: Wiley-VCH)

[141] Ruh A, Piotter V, Plewa K, Ritzhaupt-Kleissl H-J and Haußelt J 2010 Effects of material improvement and injection moulding tool design on the movability of sintered two-component micro parts Microsyst. Technol. In press; DOI: 10.1007/s00542-010-1128-3

[142] Gietzelt T, Piotter V, Jacobi O, Ruprecht R and Hausselt J 2003 Fabrication of micromolds for gearwheels by micro powder injection molding Adv. Eng. Mater. 5 139-45

[143] Yoshikawa K and Ohmori H 2001 Outstanding features of powder injection molding for micro parts manufacturing RIKEN Review pp 13-8

[144] Meng J, Loh N H, Fu G, Tor S B and Tay B Y 2010 Replication and characterization of 316L stainless steel micro-mixer by micro powder injection molding J. Alloys Compd. 496 293-9

[145] Piotter V, Finnah K, Plewa R, Ruprecht R and Hausselt J 2005 High-resistive micro components produced by high-pressure powder injection moulding Proc. 4M Int. Conf. Elsevier ISBN 0-08044879-8 pp 207-10 